\title{
La inmunidad de las organizaciones internacionales y de sus funcionarios cuando son nacionales del Estado sede. Diferencias con la inmunidad diplomática y experiencias de la jurisprudencia internacional y colombiana
}

\section{The Immunity of International Organizations and their Officials when they are Nationals of the Host State. Differences with Diplomatic Immunity and Experiences from International and Colombian Case Law}

L'immunite des organisations internationales et de ses fonctionnaires quand ils ont la nationalite de l'Etat siege. Differences avec l'immunite diplomatique et les experiences de la jurisprudence internationale et colombienne

\author{
Ricardo Abello-Galvis* \\ Walter Arévalo-Ramírez ${ }^{* *}$
}

\begin{abstract}
SUMARIO: I. Introducción: el objeto y fin de las organizaciones internacionales como parámetro de su inmunidad. El convenio constitutivo y el acuerdo de sede como puntos de partida. II. El fundamento convencional de la inmunidad de los funcionarios de las organizaciones internacionales y su relación con los privilegios concedidos por el Estado sede. III. Doctrina y jurisprudencia internacional sobre las principales diferencias entre la inmunidad diplomática y la inmunidad de las organizaciones internacionales que sustentan la inmunidad de sus funcionarios nacionales del Estado sede. IV. La inmunidad de las organizaciones internacionales en la jurisprudencia constitucional colombiana: recepción del principio y confusión de su alcance.

V. Conclusión. VI. Agradecimientos. VII. Bibliografía.
\end{abstract}

* Universidad del Rosario, Colombia; ORCID ID: https: / / orcid.org/0000-0002-4538-9748.

** Universidad del Rosario, Colombia; ORCID ID: https: / / orcid.org/0000-0002-8501-5513, walter.arevalo@urosario.edu.com. 
RESUMEN: El presente artículo analiza la inmunidad de las organizaciones internacionales y la de sus funcionarios cuando son nacionales del Estado sede, estableciendo diferencias con la inmunidad diplomática. En primer lugar, el artículo estudia el objeto y fin de las organizaciones internacionales como parámetro de su inmunidad. Luego, se analiza el fundamento convencional de la inmunidad de los funcionarios de las organizaciones internacionales y su relación con los privilegios concedidos por el Estado sede. En tercer lugar, el artículo profundiza en las principales diferencias entre la inmunidad diplomática y la inmunidad de las organizaciones internacionales que sustentan la inmunidad de sus funcionarios nacionales del Estado sede, a través de la doctrina y jurisprudencia internacionales y comparadas, abordando casos paradigmáticos de su recepción y defensa ante tribunales nacionales cuando autoridades y jueces locales han querido limitar el alcance de la inmunidad de las organizaciones y sus funcionarios, como ha ocurrido en Estados Unidos, Bélgica y Colombia, entre otros.

Palabras clave: inmunidad de las organizaciones internacionales, inmunidad diplomática, Estado sede, funcionarios nacionales, inmunidad funcional.

ABSTRACT: The article analyzes the immunity of international organizations and their staff and officials when they are nationals of the host State, establishing differences with diplomatic immunity. In first place, the article studies the object and purpose of international organizations as a parameter of their immunity. Then, the conventional basis for the immunity of officials of international organizations and its relationship with the privileges granted by the host State. As a third point, the article delves into the main differences between diplomatic immunity and the immunity of international organizations, that uphold the immunity of their officials that are also national of the host State, through international and comparative doctrine and jurisprudence, addressing paradigmatic cases of the reception and defense of such principles before national courts when local authorities and judges have wanted to limit the scope of immunity for organizations and their officials, as has happened in United States, Belgium and Colombia, among others.

Key words: immunity of international organizations, diplomatic immunity, host State, national officials, functional immunity.

RÉSUMÉ: Cet article analyse des immunités des organisations internationales, ainsi que de ses fonctionnaires quand ceux-ci ont la nationalité de l'État siège, en établissant les différences avec l'immunité diplomatique. En premier lieu, l'article aborde l'objet et le but des organisations internationales, ainsi que de leur immunité. Ensuite, il étudie la base conventionnelle de l'immunité des fonctionnaires des organisations internationales et son lien avec les privilèges octroyés par l'État siège. En troisième lieu, l'article signale les différences principales entre l'immunité diplomatique et l'immunité des organisations internationales qui sont à la base de l'immunité des fonctionnaires qui ont la nationalité de l'État siège. Pour ce faire, nous prenons en compte la doctrine et la jurisprudence internationales et comparées en analysant les affaires paradigmatiques, leur réception et défense auprès des tribunaux nationaux quand les autorités et les juges de droit interne ont essayé de limiter la portée de l'immunité des organisations et de leurs fonctionnaires, comme c'est déjà arrivé aux États Unis, en Belgique et en Colombie.

Mots-clés: immunité des organisations internationales, immunité diplomatique, État siège, fonctionnaires nationaux, immunité fonctionnelle. 


\section{INTRODUCCIÓN: EL OBJETO Y FIN DE LAS ORGANIZACIONES INTERNACIONALES COMO PARÁMETRO DE SU INMUNIDAD. EL CONVENIO CONSTITUTIVO Y EL ACUERDO DE SEDE} COMO PUNTOS DE PARTIDA

La premisa introductoria sobre la inmunidad de las organizaciones internacionales, consiste en que el alcance convencional de la misma y las actividades cobijadas por ella dependen del objeto y fin de la organización internacional, ${ }^{1}$ bien sea en lo expresamente planteado en los artículos del tratado, o como en lo que se interprete de sus poderes inherentes y los de sus órganos. Este enfoque de la inmunidad de las organizaciones internacionales se conoce como inmunidad de carácter funcional. ${ }^{2}$

Tanto la inmunidad de la persona jurídica internacional ${ }^{3}$ que ha sido creada por el acto constitutivo, como los privilegios e inmunidades que gocen sus órganos y funcionarios en el Estado sede, siempre estarán determinadas por actividades que se consideren propias del objeto y fin de la organización. Lo anterior implica que la adecuada defensa de las inmunidades de las organizaciones internacionales pactadas en su acto constitutivo requiere de la interpretación del objeto y fin de la organización, aplicando los criterios de factor textual, poderes inherentes y principio de especialidad, desarrollados por la Corte Internacional de Justicia. ${ }^{4}$

Los criterios de interpretación del objeto y fin, y la debida aplicación del principio de especialidad ${ }^{5}$ son de total relevancia en la materia porque en muchas ocasiones las autoridades locales pueden poner en duda la inmuni-

1 Klabbers, Jan, An Introduction to International Organizations Law, 3a. ed., Cambridge, Cambridge University Press, 2015.

2 Tesfagabir, Kibrom, "The State of Functional Immunity of International Organizations and their Officials and why it Should be Streamlined", Chinese Journal of International Law, vol. 10, núm. 1, 2011, pp. 97-128.

3 Gazzini, Tarcisio, "Personality of International Organizations", Research Handbook on the Law of International Organizations, núm. 33, 2011.

4 Corte Internacional de Justicia (en adelante CIJ), "Legality of the Use by a State of Nuclear Weapons in Armed Conflict” (Opinión Consultiva), 1996.

5 Arevalo-Ramirez, Walter, Manual de derecho internacional público. Fundamentos, tribunales internacionales y casos de estudio, 2a. ed., Bogotá, Tirant lo Blanch, 2020. 
dad de los funcionarios de una organización internacional, (por ejemplo, por la sospecha de que al ser nacionales no deberían recibir un trato distinto a los connacionales, o por considerar los hechos como totalmente fuera del objeto, como acusaciones de acoso sexual y laboral al staff de la organización, como ocurrió en el caso Mendaro v.World Bank ante las cortes federales de EE UU $)^{6}$ y serán los mismos órganos de la organización los que invocarán la interpretación adecuada de su objeto y fin, ${ }^{7}$ sus poderes inherentes, el alcance del principio de especialidad respecto a su mandato, y serán los primeros competentes para dictaminar e invocar si la actividad realizada por sus funcionarios se encuentra cobijada por la inmunidad funcional.

De igual manera, bajo el concepto de "efecto útil" dentro de la teoría de los tratados, son los órganos de las organizaciones internacionales los competentes para, prima facie, dictaminar autónomamente ${ }^{9}$ si el comportamiento de un órgano u agente se realizó con la intención de darle efectividad y cumplimiento al mandato recibido por la propia organización internacional por parte de los Estados en su tratado constitutivo, y complementariamente en su acuerdo de sede, acuerdo que habitualmente desarrolla con el Estado sede, el objeto y fin de la organización, así como algunos preceptos concretos de su inmunidad en el Estado sede ${ }^{10}$, como su alcance en lo jurisdiccional y administrativo, o la existencia de excepciones o waivers a la inmunidad en materias como la laboral, la tributaria, la migratoria, la electoral u otras frente a las autoridades locales.

6 Mendaro vs.World Bank, 717 F.2d 610 (D.C. Cir. 1983).

7 Berenson, William M., "Squaring the Concept of Immunity with the Fundamental Right to a Fair Trial: The Case of OAS”, TheWorld Bank Legal Review, 2012, p. 133.

8 Para una definición de "efecto útil" en materia de derecho de los tratados y las organizaciones internacionales, véase la Opinión Consultiva de la CIJ "Interpretation of the Agreement of 25 March 1951 between the WHO and Egypt”, de 1980.

9 "From a formal standpoint, the constitutive instruments of international organizations are multilateral treaties, to which the well-established rules of treaty interpretation apply... But the constitutive instruments of international organizations are also treaties of a particular type; their object is to create new subjects of law endowed with a certain autonomy, to which the parties entrust the task of realising common goals. Such treaties can raise specific problems of interpretation owing, inter alia, to their character which is conventional and at the same time institutional”. CIJ, Legality of the Use by a State of Nuclear..., cit. pp. 74 y 75.

10 Vargas, Juan Carlos y Rodriguez-Weil, Eduardo, "La inmunidad de jurisdicción y ejecución de las organizaciones internacionales: un tema antiguo con relevancia actual”, Anuario Hispano-Luso-Americano de Derecho Internacional, vol. 21, 2013, pp. 511-538. 


\author{
II. EL FUNDAMENTO CONVENCIONAL DE LA INMUNIDAD \\ DE LOS FUNCIONARIOS DE LAS ORGANIZACIONES \\ INTERNACIONALES Y SU RELACIÓN CON LOS PRIVILEGIOS \\ CONCEDIDOS POR EL ESTADO SEDE
}

Para las organizaciones internacionales, el atributo de la inmunidad, igual que el de poseer personalidad jurídica, tener presupuesto propio, la existencia de una sede permanente, la independencia de sus órganos respecto de los Estados que la han creado, ${ }^{11}$ entre otras características, no es más que un mecanismo esencial para garantizar el cumplimiento de su objeto y fin en la medida y alcance que lo han consagrado los Estados en el mandato otorgado por ellos a la organización en su acto constitutivo.

La inmunidad, es el prerrequisito para el ejercicio de las funciones internacionales de la organización sin ninguna interrupción en el ámbito internacional, pero especialmente, como garantía cuando estas actividades se llevan a cabo en el territorio de sus Estados parte, y más aún en la relación diaria con las autoridades del Estado sede que la alberga funcionalmente en su territorio. ${ }^{12}$

En atención a la complejidad de la institucionalidad y asuntos políticos que atraviesan los Estados modernos en su funcionamiento organizacional hoy en día, estas inmunidades se contemplan como una salvaguarda a posibles interrupciones o interferencias que puedan provenir de cualquier rama del poder público del Estado, que busquen en lo internacional o en lo local contradecir o truncar la actividad de la organización y la de sus agentes.

Por ello, usualmente las inmunidades funcionales se plantean de manera absoluta frente a cualquier acción administrativa o judicial relativa a hechos cobijados por las funciones propias de la organización. ${ }^{13}$

11 Téllez Nuñez, A., “Aproximación multidimensional al régimen de responsabilidad internacional y al principio de no intervención. El problema hermenéutico”, Anuario Colombiano de Derecho Internacional, vol. 13, 2020, pp. 79-104, disponible en: https: / /doi.org/10.12804/ revistas. urosario.edu.co/acdi /a. 7492.

12 Evans, Malcolm, International Law, 5a. ed., Oxford, Oxford University Press, 2018.

13 Pajuste, Tiina, “The Evolution of the Concept of Immunity of International Organizations”, East-West Studies: Journal of Social Sciences of Tallinn University Law School, vol. 8, 2018. 
La concepción de la inmunidad de las organizaciones internacionales como una derivada de su objeto y fin, y como una inmunidad que en la actualidad se considera como funcional independientemente de que se pacte de manera absoluta o restringida, ha sido la aproximación a la inmunidad de mayor recibo en el ámbito latinoamericano y así ha sido reflejada no sólo en los acuerdos de sede y tratados constitutivos de varias organizaciones internacionales creadas o conformadas por Estados latinoamericanos, sino que además esta concepción ha sido cristalizada en el contexto de la Organización de Estados Americanos (OEA) por su principal órgano codificador del derecho internacional, el Comité Jurídico Interamericano.

En efecto, este último, ha proferido una serie de lineamientos sobre el alcance de la inmunidad jurisdiccional de carácter funcional, las obligaciones correlativas que ésta implica para las organizaciones internacionales, y las prácticas subsecuentes de los Estados en observancia de tal inmunidad:

Lineamiento 2. Objetivo de la inmunidad jurisdiccional

La inmunidad jurisdiccional se otorga a las organizaciones internacionales para hacer posible la realización de su objeto y fin.

Notas del Relator

El tratado constitutivo de una organización internacional tiene como consecuencia la creación de una persona jurídica con capacidad jurídica y patrimonio propio. El artículo 104 de la Carta de las Naciones Unidas al establecer que "la Organización gozará, en el territorio de cada uno de sus Miembros, de la capacidad jurídica que sea necesaria para el ejercicio de sus funciones y la realización de sus propósitos", fijó un criterio fundamental de toda organización internacional. Los privilegios e inmunidades son concedidos para que pueda realizar la función para la que fue creada. La citada Carta, en su artículo 105, párrafo 1, así lo señala: "La Organización gozará, en el territorio de cada uno de sus Miembros, de los privilegios e inmunidades necesarios para la realización de sus propósitos”.

En tal sentido, así se manifiesta un informe del Comité Jurídico Interamericano:

En el ámbito interamericano, el mismo tenor se encuentra en la Carta de la Organización de los Estados Americanos cuyo artículo 133 establece que la organización “...gozará en el territorio de cada uno de sus miembros de la capacidad jurídica, 
privilegios e inmunidades que sean necesarios para el ejercicio de sus funciones y la realización de sus propósitos”. En el caso del Banco Interamericano de Desarrollo su Convenio Constitutivo establece que "para el cumplimiento de su objetivo y la realización de las funciones que se le confieren, el Banco gozará, en el territorio de cada uno de los Países miembros, de la situación jurídica, inmunidades, exenciones y privilegios que en este artículo se establecen”. El Convenio Constitutivo del Banco permite el establecimiento de acciones judiciales en la medida que el objeto del Banco es proporcionar financiamiento a los Estados miembros para proyectos de desarrollo y, como parte de su actividad, debe emprender acciones ante tribunales nacionales. La inmunidad entonces es estrictamente funcional y permite, en este caso, el inicio de procedimientos para consecución del objeto y fin del Banco. Los Estados miembros han otorgado inmunidad jurisdiccional a las organizaciones internacionales para facilitar el logro de sus objetivos con independencia, economía y sin obstáculos que, de otra manera, pudieran enfrentar por medio de la competencia jurisdiccional que ejerzan tribunales de algún Estado miembro frustrando la voluntad de la mayoría de los Estados miembros.

El fin último de esa inmunidad de jurisdicción es asegurar la independencia de la organización y evitar la interferencia indebida en la ejecución de su mandato. De no ser así, una organización estaría sujeta a todo tipo de acciones judiciales que imposibilitarían su trabajo. En el caso Amaratunga v. Northwest Atlantic Fisheries Organization, la Suprema Corte de Canadá estableció que sin inmunidad una organización internacional sería vulnerable a interferencia en sus operaciones por el Estado receptor y por los tribunales de ese Estado. ${ }^{14}$

Lo anteriormente codificado por la OEA fue también claramente ejemplificado por la Corte Suprema de Canadá en el caso Amaratunga v. Northwest, relativo a la Organización Pesquera del Atlántico Noroccidental NAFO, que como referente jurisprudencial paradigmático en el ámbito comparado ${ }^{15}$, recalcó el principio de que la inmunidad de las organizaciones se deriva

14 Informe del Comité Jurídico Interamericano, "Inmunidades de las organizaciones internacionales”, 93o. Período Ordinario de Sesiones, documento CJI/doc.554/18 rev.2, Rio de Janeiro, Brasil, 16 de agosto de 2018.

Para más información sobre el citado caso en esta transcipción, véase Amaratunga $v$. Northwest Atlantic Fisheries Organization, 2013, disponible en: https: / /scc-csc.lexum.com/scc-csc/ scc-csc/en/item/13364/index.do.

15 Van Ert, Gib; Allen, Greg J. y Robb, Rebecca, “Canadian Cases in Public International Law in 2013”, Canadian Yearbook of international law, vol. 51, 2013, p. 535. 
única y exclusivamente del tratado y no puede ser arbitrariamente limitada por las autoridades locales.

En el caso en cuestión la Corte Suprema de Canadá reivindicó la necesidad de que las instituciones y agentes nacionales respeten la inmunidad pactada a toda costa y no deriven excepciones a la misma ni de las normas locales ni de conflictos que emergen entre los sujetos privados y la organización, salvo que tales excepciones están expresamente pactadas en el acuerdo constitutivo o en el acuerdo de sede, como el de este caso específico:

NAFO is an international organization headquartered in Nova Scotia. Its mandate is to manage and preserve fishing resources in the Northwest Atlantic Ocean. A worked at NAFO as a senior manager from 1988 until 2005 when NAFO terminated his employment. When A then commenced a wrongful dismissal suit, NAFO claimed immunity as an international organization under its Northwest Atlantic Fisheries Organization Privileges and Immunities Order ("NAFO Immunity Order") agreement with Canada. The Supreme Court of Nova Scotia rejected NAFO's immunity defence and determined that A's wrongful dismissal suit could proceed to trial, including A's claim for a separation indemnity under NAFO Staff Rules. The Court of Appeal, however, allowed NAFO's appeal and determined that NAFO enjoyed immunity from all of A's claims.

Held: The appeal should be allowed in part.

NAFO is entitled to immunity, except from A's separation indemnity claim under the Staff Rules. Without immunity, an international organization would be vulnerable to intrusions into its operations by the host state and that state's courts. However, no rule of customary international law confers immunity on international organizations. Instead, they derive their immunity from treaties, or in the case of smaller international organizations like NAFO, from agreements with host states $[\ldots]$ To allow employment related claims of senior officials to proceed in Canadian courts would constitute undue interference with NAFO's autonomy in performing its functions and would amount to submitting its managerial operations to the oversight of its host state's institutions. The absence of a dispute resolution mechanism or of an internal review process is not, in and of itself, determinative of whether NAFO is entitled to immunity. While the fact that A has no forum in which to air his grievances and seek a remedy is unfortunate, it is the nature of an immunity to shield certain matters from the jurisdiction of the host State. 
Casos como el anterior en donde la inmunidad de las organizaciones internacionales es retada unilateralmente por los Estados que buscan establecer restricciones a su alcance, por ejemplo en temas laborales, o a cierto tipo de funcionarios, o pretenden aplicarle restricciones que consideran típicas de una concepción de inmunidad restringida, son fundamentales para reivindicar a nivel jurisprudencial las profundas diferencias entre la inmunidad de las organizaciones internacionales y la inmunidad de las misiones diplomáticas (heredera de la inmunidad del Estado). ${ }^{16}$

En materia de misiones diplomáticas, la inmunidad, al no emanar de lo pactado en un instrumento concreto, como ocurre con cada una de las organizaciones internacionales en su propio acuerdo constitutivo (y/o acuerdo de sede cuando este precisa más a fondo las inmunidades), sino alimentarse como fuente de la soberanía del Estado en sus relaciones internacionales, la aplicación de principios westfalianos como la igualdad entre Estados y la imposibilidad de actos de imperio entre pares, "Non enim una civitas potest facere legem super alteram, quia par in parem non habet imperium", todos recogidos en la costumbre internacional, suele admitir restricciones, excepciones, y toda suerte de limitaciones reguladas por la costumbre ${ }^{17} \mathrm{y}$ aplicadas a todas las misiones diplomáticas, asunto distinto al mundo de las organizaciones internacionales donde la inmunidad de cada una de ellas merece un análisis ad hoc de sus instrumentos convencionales.

Por lo anterior, es fundamental entender las diferencias entre los dos tipos de inmunidad y sus orígenes para poder comprender el verdadero alcance de la inmunidad de las organizaciones internacionales, especialmente cuando es concedida a los funcionarios que son nacionales del Estado sede donde se asienta la organización o en oficinas donde desarrollan sus funciones.

La inmunidad de las organizaciones internacionales es un desarrollo rápido, práctico, y propio del derecho internacional en el siglo XX donde el instrumento dominante son los tratados; en cambio, la inmunidad de los

16 Barker, J. Craig; Colin, Warbrick y McGoldrick, Dominic, "State Immunity, Diplomatic Immunity and Act of State: A Triple Protection against Legal Action?", The International and Comparative Law Quarterly, vol. 47, núm. 4, 1998, pp. 950-958.

17 Abello-Galvis, Ricardo, "La Costumbre como fuente de derecho internacional: una caja de pandora imposible de cerrar", Derecho internacional: varias visiones, un maestro. Liber amicorum en homenaje a Marco Gerardo Monroy Cabra, Bogotá, Universidad del Rosario, 2015, pp. 3-28. 
Estados ${ }^{18}$ y las misiones diplomáticas, no se circunscriben al ámbito meramente funcional, sino que se alimenta del concepto de soberanía y de las costumbres internacionales encaminadas a proteger a los jefes de Estado, extendiéndose progresivamente en la historia a sus enviados al extranjero, pero limitada por vía consuetudinaria a actos de Estado, admitiendo históricamente, gran cantidad de excepciones, que en el momento de ser concebidas no contemplaban ni pretendían regular, ni el concepto futuro de "funcionario internacional" de una organización, ni mucho menos la posibilidad más moderna de que una organización internacional empleara a nacionales de su Estado sede como funcionarios y requiriera dotarlos de inmunidad en el mismo territorio de donde son nacionales para poder realizar libremente sus funciones:

The immunity granted to IOs comes from the foreign sovereign immunities tradition mentioned above. However, it is justified by a theory of "functional necessity", which came into being after World War II, when emerging IOs needed support from the States in order to achieve a certain degree of maturity and therefore to be able to perform their duties in an unfettered manner. This kind of immunity was based on the idea that it would serve the best interests of the organizations by keeping them protected from potential lawsuits that would negatively affect the organizations' limited resources at that time or their ability to operate independently. For IOs, immunity was supposed to ensure their political and financial independence and therefore their impartiality. Since immunity of IOs came into being before the restrictive immunity theory had been adopted by many sovereign states, it was conceived and codified as being absolute. Many of these organizations actually have it codified in their own constituent instruments and other international treaties. It can also exist in the form of headquarters agreements, regional agreements, and conference agreements. These treaties, due to their international law character, are to be considered internal law of the signatory States (at least for those in which treaty law is self-executing). ${ }^{19}$

18 Quintana Aranguren, Juan José y Guzmán Carrasco, Gonzalo, "De espaldas al derecho internacional: Colombia y la inmunidad de jurisdicción de los Estados", International Law: Revista Colombiana de Derecho Internacional, núm. 8, 2006, pp. 53-102.

19 Rios, Greta L. y Flaherty, Edward P., "International Organization Reform of ImpunityImmunity is the Problem”, ILSA J. Int'l \& Comp. L., vol. 16, 2009, pp. 433. 
III. DOCTRINA Y JURISPRUDENCIA INTERNACIONAL SOBRE LAS PRINCIPALES DIFERENCIAS ENTRE LA INMUNIDAD DIPLOMÁTICA Y LA INMUNIDAD DE LAS ORGANIZACIONES INTERNACIONALES QUE SUSTENTAN LA INMUNIDAD DE SUS FUNCIONARIOS NACIONALES DEL ESTADO SEDE

Como se ha venido anticipando, la principal diferencia radica en que la inmunidad de las organizaciones internacionales es un asunto convencional, especialmente en materia de excepciones y limitaciones, mientras que la naturaleza implícita de la inmunidad diplomática es ser una inmunidad de arraigo consuetudinario cuyas excepciones también emanan de la costumbre universal. ${ }^{20} \mathrm{La}$ inmunidad de las organizaciones internacionales siempre se identifica caso a caso, en el tratado constitutivo de la organización, donde se debe identificar en qué términos ha sido pactada, y las excepciones pactadas a ella no pueden derivarse de la práctica de los Estados o de la costumbre.

Por el contrario, es justamente la práctica de los Estados y la costumbre, tanto en el alcance de la inmunidad diplomática como sus limitaciones, la que ha sido recogida en el instrumento principal de carácter codificador de costumbre en la materia, la Convención de Viena sobre Relaciones Diplomáticas. $^{21}$

Esto no niega el hecho que muy rápidamente algunos aspectos de la inmunidad de las organizaciones internacionales no hubiesen adquirido un estatus consuetudinario. ${ }^{22}$ Los tribunales nacionales en repetidas ocasiones le han dado este fundamento a la existencia y la necesidad de la inmunidad funcional ${ }^{23}$ para las organizaciones internacionales en su territorio y han

20 Portilla Parra, Sebastian y Rodríguez Bolaños, Maicol Andrés, “Aplicación y límites de la inmunidad diplomática, a la luz de las normas del «ius cogens»”, Opinión Jurídica, vol. 19, núm. 38, 2020, pp. 259-281.

21 Convención de Viena de 1961 sobre Relaciones Diplomáticas, aprobada por Ley $6^{\circ}$ de 1972, en vigor para Colombia.

22 Wood, Michael, "International Organizations and Customary International Law", Vanderbilt Journal of Transnational Law, vol. 48, núm. 3, 2015, p. 609.

23 Godio, Leopoldo, "Evolución, actualidad y tendencias en materia de privilegios e inmunidades de organismos internacionales”, RECORDIP, vol. 1, núm. 2, 2011. 
reconocido consuetudinariamente a la inmunidad de jurisdicción como un principio que no viola la soberanía nacional, pero esto no significa que las excepciones y limitaciones a tal inmunidad existan fuera de las expresamente pactadas en el acuerdo constitutivo o en el acuerdo de sede de cada una de las organizaciones y que se puedan aplicar universalmente por los tribunales nacionales, como sí ocurre con la inmunidad diplomática donde sus límites consuetudinarios son ampliamente aceptados. ${ }^{24}$

Esta recepción de la inmunidad de las organizaciones internacionales por parte de los tribunales nacionales ${ }^{25}$ ha incluso llegado a que sea reconocida como un principio de derecho internacional en decisiones judiciales ${ }^{26}$ que indicaron que los tribunales nacionales no pueden interpretar de manera restrictiva la inmunidad de las organizaciones internacionales al equipararla a la inmunidad diplomática, siendo esta una decisión ultra vires. ${ }^{27}$ Así fue reconocido en un primigenio fallo de los tribunales belgas de apelación en el caso Manderlier, que reconocieron que las cortes belgas no podían interpretar de manera restrictiva la Convención de Naciones Unidas sobre Privilegios e Inmunidades ${ }^{28}$ ni siquiera bajo la idea de permitir el derecho al acceso a la justicia de un demandante en contra de la organización, por ser la demanda ante los tribunales nacionales una evidente limitación a su inmunidad.

With regard to the argument that Article 105 of the United Nations Charter limited the privilege of immunity to the minimum necessary to enable the United Nations to fulfil its purposes, the Court replied that in acceding to

24 Brown, Jonathan, "Diplomatic Immunity: State Practice under the Vienna Convention on Diplomatic Relations”, International and Comparative Law Quarterly, vol. 37, núm. 1, 1988 , p. 53.

25 Reinisch, August, International Organizations before National Courts, Cambridge, Cambridge University Press, 2000.

26 Decisiones de tribunales nacionales que reconocen la condición convencional de la inmunidad jurisdiccional plena de las organizaciones internacionales, véase $X$ et al. v. European School, Munich, I63 the Bavarian appellate Administrative Court; US-Iran Claims Tribunal v AS, 96 ILR 321, 329 (Netherlands Supreme Court, 1985).

27 Brussels Appeals Court, Manderlier v. United Nations and Belgian State, decision of 15 th September 1969, disponible en: https: //legal.un.org/unjuridicalyearbook/pdfs/english/by_volu me/1969/chpVIII.pdf

28 Miller, Anthony, "Privileges and Immunities of United Nations Officials", International Organizations Law Review, vol. 4, núm. 2, 2008, pp. 169-257. 
the Convention of 13 February 1946, the signatories of the Charter had defined the necessary privileges and immunities and that the courts would be exceeding their authority if they were to arrogate to themselves the right of determining whether the immunities granted to the United Nations by that Convention were or were not necessary. ${ }^{29}$

Este pilar esencial de la inmunidad funcional de las organizaciones internacionales en su naturaleza convencional ha sido también reconocido por el Comité Jurídico Interamericano en su lineamiento sobre las renuncias expresas a la inmunidad: "Alcance de la inmunidad jurisdiccional. Las organizaciones internacionales, sus bienes y haberes gozan de inmunidad contra todo procedimiento judicial respecto de actos realizados para la consecución de su objeto y fin, salvo en los casos que la organización renuncie expresamente a esa inmunidad". ${ }^{30}$

29 Brussels Appeals Court. Manderlier v. United Nations and Belgian State, cit.

30 Informe del Comité Jurídico Interamericano, op. cit. Sin embargo, hace noytar en dicho documento que Joel Hernández García en el Plan de Trabajo, 1er informe del relator (documento CJI/doc.486/15 del 30 de julio de 2015, en una nota del relator dice:

A partir de la práctica de los Estados, han surgido tres doctrinas sobre la naturaleza de la inmunidad: inmunidad absoluta, inmunidad restringida-clásica y la inmunidad funcional. Como se comentó en las notas al lineamiento 1 supra, la inmunidad absoluta fue reconocida a los Estados extranjeros en virtud del principio par in parem non habet imperium. Los Estados gozan de inmunidad ante los tribunales de otros Estados por virtud del principio de igualdad jurídica de los Estados. La necesidad de evitar la inmunidad de conductas que excedían el objeto de la función estatal tuvieron como consecuencia el establecimiento de límites a la inmunidad absoluta dando paso a una inmunidad restringida de los Estados. El concepto de inmunidad restringida clásica se aplica a los gobiernos soberanos bajo el derecho internacional y se basa en el principio de que un Estado al entrar en el mercado comercial para comprar y/o vender servicios y bienes, debe ser tratado como cualquier actor comercial y sujeto a la competencia de tribunales nacionales.

En lo que corresponde a organizaciones internacionales, la inmunidad tiende a ser funcional con base en la presunción de que sólo corresponde reconocer esa inmunidad para las actividades de las organizaciones que sean esenciales y necesarias para lograr su objeto y fin. Los estatutos de cada organización establecen los actos inherentes al fin de la organización y, por tanto, cubiertos por la inmunidad. Sin embargo, los Estados Miembros establecen el alcance de la inmunidad jurisdiccional a ser reconocida por sus tribunales nacionales. Al mismo tiempo, el Estado anfitrión acuerda con la organización el tipo de inmunidad jurisdiccional que gozará en su territorio.

La inmunidad jurisdiccional se otorga a la organización internacional como tal y cubre los actos que realice en consecución de su objeto y fin. En tal virtud, el patrimonio de la 
Las lógicas que diferencian en el día a día las inmunidades de las organizaciones internacionales a las de la inmunidad la diplomática, y que son fundamento después del alcance diferenciado que éstas tienen en los nacionales del Estado en donde desempeñan sus funciones, muchas veces parten de situaciones evidentes de las relaciones internacionales que después deben ser elaboradas en lo jurídico. Una de aquellas realidades evidentes es que las organizaciones internacionales al no contar con su propio territorio para instalar a sus órganos y agentes, y ejercer libremente sus potestades, siempre se encuentran en el territorio de un Estado parte que ha decidido ser su Estado sede (Host State), lo que necesariamente hace que siempre se encuentren a la merced de alguna posibilidad de vulnerabilidad e intromisión de autoridades administrativas o jurisdiccionales de aquel Estado. Esta condición que podemos denotar como su "no territorialidad" ha sido considerada por la doctrina como una de las principales razones para respetar de manera plena la inmunidad jurisdiccional convencional a ellas otorgada:

The immunity from jurisdiction of international organizations is generally analyzed by comparison with the immunity of States. The principal argument advanced to justify the differences in nature between the two is that national organizations have no territory. Their independence can, therefore, only be guaranteed by a strict approach to their immunity, in particular respect to the courts of the State in which their headquarters are located. Been observed that the organization must benefit "in any event from degree of protection at the place of its seat, which can be guaranteed by immunity formulated in relatively broad, if not absolute, terms". Various decisions reflect this idea, typically framing it as a fundamental principle. Such line of reasoning embraces in absolute terms both the existence and scope of immunity of international organizations. One could reasonably concede that the recognition of immunity to an international organization lacks territory and is established on the territory of a State is justified primarily by the necessity of precluding any undue interference by the host State activities of that organization. ${ }^{31}$

organización se encuentra también protegido. Aunque el alcance de esta Guía se limita a la inmunidad jurisdiccional, conviene precisar que la inmunidad jurisdiccional cubre a los bienes y haberes, a fin de dejarlos salvaguardados frente a cualquier reclamación que enfrente la organización internacional.

31 Gaillard, Emmanuel y Pingel-Lenuzza, Isabelle, "International Organizations and Immunity from Jurisdiction: To restrict or to Bypass", International and Comparative Law Quarterly, vol. 51, núm.1, 2002, pp. 1-15. 
Lo anterior también es cierto respecto a la interrogante de dónde obtener a los funcionarios que conformarán los órganos de la organización internacional. A diferencia de los Estados, las organizaciones internacionales no tienen población, por lo que es natural que conformen su cuerpo de funcionarios con nacionales de los Estados parte y específicamente que encuentren en los nacionales que viven en el Estado sede, un inmenso insumo para el cuerpo de funcionarios.

Es por eso que, a diferencia de las misiones diplomáticas, la inmunidad de los funcionarios de las organizaciones internacionales no emana ni se exceptúa según su vínculo de nacionalidad, como ocurre con los miembros de la misión diplomática acreditados en el extranjero y con otras instituciones de derecho internacional basadas en la nacionalidad, como la protección diplomática. ${ }^{32}$

Esta diferencia es vital y no debe confundirse con la razón por la cual en materia de inmunidad diplomática las personas que son nacionales del Estado donde se encuentra la misión diplomática (Estado receptor), y que se ponen a disposición de aquella por vía laboral o por situaciones como la doble nacionalidad, no adquieren inmunidad.

En efecto, en materia de inmunidad diplomática, la práctica ha demostrado que en tanto los Estados cuentan con su servicio diplomático conformado por sus propios nacionales, es absolutamente inusual, salvo situaciones muy específicas de doble nacionalidad, que un Estado elija como su representante en el extranjero ante un Estado receptor, en vez de a uno de sus nacionales, a un ciudadano que sea nacional de ese Estado que recibe la misión diplomática. Por ello, la costumbre en materia de inmunidad diplomática ha derivado en que a estos funcionarios de misión diplomática que son nacionales del Estado receptor no se les conceda inmunidad al momento de acreditarlos, práctica codificada como costumbre en la Convención de Viena sobre Relaciones Diplomáticas, pero de nuevo, así planteada por las razones particulares aplicables sólo a misiones diplomáticas y no a organizaciones internacionales.

Esta excepción, tanto consuetudinaria como recogida por el instrumento cristalizador de la Convención de Viena, ha llegado al punto de aceptar

32 MacLean, Robert Joseph-Blaise y Arévalo-Ramírez, Walter, “The Expulsion of Resident Colombian Nationals during the Colombia-Venezuela Border Dispute: An «under the Radar» Case for Diplomatic Protection of Human Rights?”, Universitas, vol. 68, núm. 138, 2019. 
que no se le conceda inmunidad a la familia del embajador ${ }^{33}$ cuando ésta es nacional del Estado receptor.

Convención de Viena sobre Relaciones Diplomáticas, del 18 de abril de 1961, la cual entró en vigor el 24 de abril de 1964 dice:

\section{Artículo 38}

1. Excepto en la medida en que el Estado receptor conceda otros privilegios e inmunidades, el agente diplomático que sea nacional de ese Estado o tenga en él residencia permanente sólo gozará de inmunidad de jurisdicción e inviolabilidad por los actos oficiales realizados en el desempeño de sus funciones.

2. Los otros miembros de la misión y los criados particulares que sean nacionales del Estado receptor o tengan en él su residencia permanente, gozarán de los privilegios e inmunidades únicamente en la medida en que lo admita dicho Estado. No obstante, el Estado receptor habrá de ejercer su jurisdicción sobre esas personas de modo que no estorbe indebidamente el desempeño de las funciones de la misión.

Aquí entonces la regla opera al contrario, sólo tendrán inmunidad los nacionales que trabajen en una misión diplomática si el Estado receptor expresamente decide concederla; en cambio, en materia de organizaciones internacionales, como lo habitual es que funcionarios con nacionalidad del Estado sede sean quienes hacen parte de la organización y cumplen sus fines dentro de los órganos, e incluso sólo se sometan al derecho laboral propio de la organización, ${ }^{34}$ la inmunidad sea concedida a ellos sin excep-

33 O'Keefe, Patrick J., "Privileges and immunities of the Diplomatic family", International and Comparative Law Quarterly, vol. 25, 1976, pp. 329-350.

Para 109 Estados, la ley aplicable que regula sus obligaciones se encuentra en el artículo 37 de la Convención de Viena de 1961 sobre Relaciones Diplomáticas. Esto dice lo siguiente:

1. The members of the family of a diplomatic agent forming part of his household shall, if they are not nationals of the receiving State, enjoy the privileges and immunities specified in Articles 29 to 36.

2. Members of the administrative and technical staff of the mission, together with members of their families forming part of their respective households, shall, if they are not nationals of or permanently resident in the receiving State, enjoy the privilege's and immunities specified in Articles 29 to 35, except that the immunity from civil and administrative jurisdiction of the receiving State specified in paragraph 1 of Article 31 shall not extend to acts performed outside the course of their duties.

34 Reinisch, August, "Contracts between International Organizations and Private Law Persons”, Max Planck Encyclopedia of Public International Law, vol 7, 2006. 
ción entre funcionarios nacionales y extranjeros, y estos funcionarios nacionales sólo se sometan a pequeñas excepciones de orden público, como pagar impuestos como sus otros connacionales o cumplir a cabalidad las reglas migratorias de entrada y salida del país, si así fueron pactadas en el acuerdo sede.

Así entonces, al ser la inmunidad de las organizaciones internacionales una inmunidad de carácter convencional y que requiere proteger a los funcionarios y agentes de la organización en el territorio del Estado sede, independientemente de su condición, lo habitual es no encontrar ninguna diferencia a priori en la protección dada vía inmunidad funcional jurisdiccional plena a funcionarios extranjeros frente a funcionarios nacionales del Estado sede, y no existe, en general, una cláusula de excepción por nacionalidad que sea común a los tratados constitutivos de organización internacional.

Por el contrario, lo que ha reconocido de manera reiterada la Corte Internacional de Justicia es que las limitaciones a la inmunidad de las organizaciones internacionales y sus agentes solamente pueden ser expresas y no es posible limitar la inmunidad jurisdiccional de manera unilateral por el Estado sede, lo que fue reconocido en las opiniones consultivas "Mazilu" ${ }^{\text {" }} \mathrm{e}$ "Immunity from Legal Process of a Special Rapporteur". ${ }^{36}$

Las diferencias entre inmunidad diplomática e inmunidad de las organizaciones internacionales se manifiestan también en los mecanismos disponibles para juzgar la responsabilidad de los funcionarios cobijados por inmunidad respecto de sus actos y la posibilidad de que ellos tengan un juez natural como consecuencia de esa inmunidad.

En el ámbito de la inmunidad diplomática, el enviado diplomático y miembro acreditado de una misión diplomática en el exterior, puede tener inmunidad frente al Estado receptor de la misión diplomática, pero siempre se encontrará sujeto a la jurisdicción disciplinaria y penal de su Estado de origen o Estado acreditante. Esta situación es también de carácter consuetudinario y ha sido codificada por la Convención de Viena sobre Relaciones Diplomáticas y Consulares. ${ }^{37}$

35 Titulada "Applicability of ArticleVI, Section 22, of the Convention on the Privileges and Immunities of the United Nations, Advisory Opinion, I.C.J. Reports 1989”, p. 177.

36 Titulada "Diference Relating to Immunity from Legal Process of a Special Rapporteur of the Commission on Human Rights, Advisory Opinion, 1. C. J. Reports 1999”, p. 62.

37 Artículo 31.4. "La inmunidad de jurisdicción de un agente diplomático en el Estado receptor no le exime de la jurisdicción del Estado acreditante”. 
Esta lógica interestatal en materia de inmunidad no puede ser utilizada para suponer que el funcionario de una organización internacional no tiene inmunidad cuando es nacional del Estado sede de la misma, pues su función no es la de un representante del Estado sujeto a las reglas del mismo, sino que, por el contrario, su inmunidad emana de aquella pactada para la organización con sus Estados parte.

Los actos de los funcionarios de las organizaciones internacionales y su juez natural no se catalogan respecto de un Estado de origen, receptor o acreditante. Para las organizaciones internacionales y sus funcionarios, bien sean nacionales del Estado sede de la misma o no, el juez natural, como lo ha demostrado la práctica, ${ }^{38}$ es la organización internacional misma mediante sus mecanismos institucionales de carácter jurisdiccional y de solución de controversias, que son competentes para disciplinar a sus funcionarios y que, incluso recientemente, han sido reconocidos como un mecanismo necesario y concomitante a las inmunidades pactadas en los tratados para la organización y sus funcionarios, para justamente respetar el derecho a la defensa de los solicitantes cuando, paradójicamente, son los mismos funcionarios los que desean accionar en contra de la organización, por ejemplo en materia laboral y no pueden hacerlo porque ella misma cuenta con inmunidad ante los tribunales locales.

Los poderes inherentes de las organizaciones internacionales para constituir este tipo de tribunales o mecanismos de solución de controversias en el contexto de su inmunidad, y como expresión de su capacidad funcional para cumplir su objeto y fin fueron reconocidos en la opinión consultiva "Effect of Awards of Compensation Made by the U.N. Administrative Tribunal" de la siguiente manera:

It was inevitable that there would be disputes between the Organization and staff members as to their rights and duties. The Charter contains no provision which authorizes any of the principal organs of the United Nations to adjudicate upon these disputes, and Article 105 secures for the United Nations jurisdictional immunities in national courts. It would, in the opinion of the Court, hardly be consistent with the expressed aim of the Charter to promote

38 Véase Resolution 1979 (2014)1 Accountability of international organizations for human rights violations, Parliamentary Assembly, Council of Europe, disponible en: https: / assembly. coe.int $/ \mathrm{nw}_{\mathrm{w}} / \mathrm{xml} / \mathrm{XRef} /$ Xref-DocDetails-en.asp?FileID=20510\&lang=en. 
freedom and justice for individuals and with the constant preoccupation of the United Nations Organization to promote this aim that it should afford no judicial or arbitral remedy to its own staff for the settlement of any disputes which may arise between it and them. ${ }^{39}$

Estos tribunales internos de las organizaciones internacionales son justamente parte del engranaje institucional de la inmunidad funcional para lograr que esta no sea vista por los Estados como una violación a su soberanía, al derecho al acceso a la justicia de cierto tipo de solicitudes frente a la organización (funcionarios de la misma que la demandan por situaciones laborales dentro de sus propios mecanismos de solución de controversias, por ejemplo) y son una razón de peso para que los Estados no intenten diluir o negar la inmunidad de los funcionarios de la organización que son nacionales del Estado sede, invocando que estos entonces no tendrían juez natural.

Casos recientes tanto en el derecho comparado como ante tribunales regionales de derechos humanos han establecido que, por un lado, estos tribunales, como parte del reconocimiento de esa inmunidad a esos funcionarios nacionales y a la organización, en su procedimiento ${ }^{40}$ deben cumplir con principios básicos de derecho procesal como los de imparcialidad, contradicción, motivación, recusación, apelación o independencia, ${ }^{41}$ como se estableció en el caso Siedler ${ }^{42}$ en 2003, en las cortes belgas.

Así también lo ha sugerido el lineamiento 6 en la materia del Comité Jurídico Interamericano de la OEA. Justamente este tipo de tribunales existen para evitar que los nacionales utilicen interpretaciones extensivas de la legislación nacional para querer someter a ciertos funcionarios (como los nacionales del Estado sede) con asuntos como los laborales, a las cortes nacionales, afectando la inmunidad como fuera pactada en el acuerdo

39 "Effect of Awards of Compensation Made by the U.N. Administrative Tribunal", Opinión Consultiva, 1954.

40 Jenks, Clarence Wilfred, The Proper Law of International Organizations, 1962.

41 Sobre el principio de independencia en derecho internacional, véase Bonyuet Lee, Díckar y Pérez Pacheco, Yaritza, "Sobre la independencia de los tribunales arbitrales CIADI", Anuario Mexicano de Derecho Internacional, México, vol. XX, 2020, pp. 273-315, disponible en: https: / / revistas.juridicas. unam. $m x /$ index.php/derecho-internacional/article/view/14477.

42 Siedler v.Western European Union, Belgian Labor Court of Appeals, Brussels, 17 de septiembre de 2003. 
constitutivo, así fue expresamente desarrollado por el Tribunal Europeo de Derechos Humanos en el caso Waite c. Alemania, relativo a las inmunidades de la Agencia Especial Europea, como se muestra a continuación:

...the Court shares the Commission's conclusion that, bearing in mind the legitimate aim of immunities of international organizations (see paragraph 63 above), the test of proportionality cannot be applied in such a way as to compel an international organization to submit itself to national litigation in relation to employment conditions prescribed under national labor law. To read Article $6 \S 1$ of the Convention and its guarantee of access to court as necessarily requiring the application of national legislation in such matters would, in the Court's view ...the proper functioning of international organizations and run counter to the current trend towards extending and strengthening international cooperation.

57. In view of all these circumstances, the Court finds that, in giving effect to the immunity from jurisdiction of ESA on the base of section 20(2) of the Courts Act, the German courts did not exceed their margin of appreciation. Taking into account in particular the alternative means of legal process available to the applicants, it cannot be said that the limitation on their access to the German courts with regard to ESA impaired the essence of their "right to a court" or was disproportionate for the purposes of Article $6 \S 1$ of the Convention. Accordingly, there has been no violation of that provision. ${ }^{43}$

Otros elementos de la costumbre y práctica de la inmunidad en materia diplomática no pueden ser equiparables a la práctica en materia de organizaciones internacionales, pues en ellos también se incluyen razones para limitar la inmunidad de los nacionales que no son admisibles ni corresponden a la razón de ser de las inmunidades de las organizaciones internacionales.

Por un lado, la inmunidad de las misiones diplomáticas se basa en el principio de reciprocidad, ${ }^{44}$ en el entendido que, en un territorio se respetan los miembros extranjeros de la misión diplomática del otro, de manera recíproca entre los dos Estados, lo que usualmente excluye a los nacionales de cada uno de los países involucrados en esa relación recíproca.

43 Waite and Kennedy vs. Germany, Merits, App No 26083/94, ECHR 1999-I, disponible en: https: / /iilj.org/wp-content/uploads/2016/08/Waite-and-Kennedy-v.-Germany.pdf.

44 Flor Patiño, Imanol de la y Portilla Gómez, Juan Manuel, "Las inmunidades diplomáticas en el derecho comparado (México-Estados Unidos) y en el derecho internacional”, Anuario Mexicano de Derecho Internacional, México, vol. XVI, 2016. 
Por otra parte, la práctica ceremonial en materia de inmunidades diplomáticas se soporta en el procedimiento de cartas credenciales y acreditación ante el Ministerio de Asuntos Exteriores del Estado Receptor, de los miembros "extranjeros" de la misión diplomática.

Este procedimiento, aunque puede ser también seguido para las organizaciones internacionales, por ejemplo, para que las oficinas de protocolo y ceremonial de estos ministerios se encarguen de otorgar a estos funcionarios los debidos privilegios e inmunidades, no puede extender a las organizaciones internacionales la denegación de la acreditación de funcionarios nacionales que aplica del derecho diplomático, o asumir que la inmunidad emana de tal acreditación, pues esta sólo emana del convenio constitutivo o del acuerdo sede y se extiende a todo proceso administrativo y penal contra la organización y los funcionarios cobijados por ella. ${ }^{45}$

Cualquier excepción a la inmunidad, incluida la posibilidad de excluir a los nacionales, como cualquier aceptación de comparecer ante los tribunales nacionales, debe emanar del tratado, expresamente mediante una excepción pactada ${ }^{46}$ (waiver), bien sea en el acto constitutivo o del acuerdo de sede, o un waiver surgido de los órganos de gobierno de la organización ${ }^{47} \mathrm{ca}-$ paces de producir derecho organizacional vinculante (resoluciones), como lo ha reiterado también el Comité Jurídico Interamericano en su lineamiento 8 (en las notas del relator), pero nunca del acto unilateral de acreditación y la decisión del Estado receptor que busque limitar la inmunidad.

A estas circunstancias de la reciprocidad y la acreditación, que no son equiparables desde la inmunidad diplomática ni la inmunidad del Estado ${ }^{48}$ a la inmunidad de las organizaciones internacionales, y por ende, a sus funcio-

45 Okeke, Edward Chukwuemeke, Jurisdictional Immunities of States and International Organizations, Oxford, Oxford University Press, 2018, p. 294.

46 "... .benefit of such immunity may be refused in some cases. For instance, it may be refused on the basis that the organization waived its immunity, although such waiver is rare. Alternatively, it may be refused because the State before whose courts the matter has been brought is not a party to the convention creating the organization, and the judge does not feel bound to grant immunity on the basis of a customary rule". Gaillard, Emmanuel y PingelLenuzza, Isabelle, "International Organizations and Immunity from Jurisdiction: To restrict or to bypass", International and Comparative Law Quarterly, vol. 51, 2002, pp. 1-15.

47 Arévalo-Ramírez, Walter, "Organizaciones Internacionales”, cit.

48 Almeida, Paula Wojcikiewicz, "L'affaire des immunités juridictionnelles de l'Etat (Allemagne c. Italie): la Cour Internationale de Justice à contre-sens de l'évolution du droit international”, Anuario Colombiano de Derecho Internacional, vol. 11, 2018, pp. 21-70. 
narios nacionales, se suma la imposibilidad de reducir la inmunidad jurisdiccional funcional absoluta de las organizaciones internacionales, emanada de sus acuerdos constitutivos, bajo la doctrina de los actos comerciales que solo tiene sentido en materia de Estados, pero, por el contrario, no es aplicable a las organizaciones internacionales, pues cuando éstas participan de operaciones comerciales cotidianas, también lo hacen para su objeto y fin:

This immunity from jurisdiction prevents law suits against organizations before domestic courts unless they have waived their immunity by consenting to the proceedings. As has been the case with State immunity, there has been pressure to restrict the absolute nature of the immunity granted to international organizations. Indeed, a number of domestic courts have applied to international organizations the concept of restrictive immunity, granting them jurisdictional immunity only in relation to acts jure imperii (in the exercise of sovereign authority) rather than acts jure gestionis (done privately). Alternatively, it has been argued that the grant of immunity should be conditional on the presence of alternative methods of resolving disputes involving international organizations (Gaillard and Pingel-Lenuzza, 2002). The first approach, which relies on an analogy with State immunity is based on the misapprehension that since international organizations are composed of States they are to be placed in the same position as foreign States. This approach is incorrect for at least two reasons. First, it is contrary to the express provisions of the relevant treaties. Secondly, international organizations are not sovereign entities and do not exercise sovereign authority. Their immunity is not granted to protect sovereign or public acts but is functional and granted in respect of acts done in the exercise of their functions. Such functions and acts may well be commercial and so classified as private if done by a State. This immunity may arise for an international organization in cases where a foreign State will be denied immunity. For example, employment disputes fall within the immunity of an international organization even if the relations with the particular employee might be classified as jure gestionis. The second approach, which conditions immunity on the existence of alternative dispute resolution mechanisms, seeks to give effect to the right of access to a court provided in human rights treaties and is reflected in the case law of the European Court of Human Rights. ${ }^{49}$

49 Evans, Malcolm, International Law, 2a. ed., Oxford, Oxford University Press, 2006, pp. 408-411. 
Desde la misma lógica de la interpretación de tratados, cuyas reglas se encuentran contenidas en el artículo 31 de la Convención de Viena sobre el Derecho de los Tratados, incorporada en la mayoría de los órdenes nacionales latinoamericanos por vía de su ratificación y sus correspondientes leyes aprobatorias de tratado o actos de incorporación, se han llegado también a conclusiones respecto a la naturaleza convencional de la inmunidad de las organizaciones internacionales. ${ }^{50}$

Por vía de la interpretación de buena fe del texto del tratado, la interpretación integradora y de efecto útil, mediante el principio ubi lex non distinguit, nec nos distinguere debemus, (no es posible distinguir por el intérprete dónde la norma no lo hace), cuando el tratado constitutivo de la organización internacional no establece esta excepción a la inmunidad de los nacionales, no le es dado hacerlo al juez nacional.

\author{
IV. LA INMUNIDAD DE LAS ORGANIZACIONES \\ INTERNACIONALES EN LA JURISPRUDENCIA \\ CONSTITUCIONAL COLOMBIANA: RECEPCIÓN \\ DEL PRINCIPIO Y CONFUSIÓN DE SU ALCANCE
}

Un caso controvertido de la recepción e interpretación de la inmunidad de las organizaciones internacionales por autoridades nacionales, que como hemos visto en la jurisprudencia internacional y comparada - previamente presentada-, ha sobrevivido como inmunidad plena, por vía de la aplicación de los preceptos antes explicados, a los embates de las jurisdicciones nacionales que buscan limitarla en distintas materias no admitidas por lo pactado en el convenio constitutivo, o negarla a los funcionarios nacionales de la organización, es el caso de la revisión constitucional en Colombia de estos preceptos de inmunidad.

En sede de la Corte Constitucional de Colombia, el debate de la inmunidad jurisdiccional de las organizaciones internacionales y de las misiones diplomáticas se ha debatido fundamentalmente por vía de sus dos competencias principales. La primera de ellas hace referencia a la competencia del

50 Por ejemplo en la legislación colombiana, mediante la ley 32 de 1985. 
control abstracto de constitucionalidad, ${ }^{51}$ donde la Corte Constitucional (de cara a las leyes aprobatorias de tratado de forma previa ${ }^{52}$ a su entrada en vigor ${ }^{53}$ dentro del proceso de ratificación, o bien, frente a las acciones públicas de inconstitucionalidad frente a esas leyes aprobatorias de tratado ${ }^{54}$ presentadas por ciudadanos de manera posterior a la entrada en vigor) analiza la constitucionalidad de distintos instrumentos que contienen preceptos de las dos inmunidades referidas.

La segunda de estas competencias es la relativa al control concreto, donde los ciudadanos, mediante la acción de tutela, pueden accionar a sujetos públicos o privados ante cualquier juez para la garantía de sus derechos fundamentales frente a una afectación concreta o limitación de ellos. En este escenario han sido numerosas las tutelas de individuos contra misiones diplomáticas, especialmente en el ámbito laboral, y también contra organizaciones internacionales por distintos derechos supuestamente afectados.

En estas ocasiones, la Corte ha llegado a las tutelas por vía de su selección para debatir la jurisdicción en relación con la existencia o no de inmunidad en esa materia, las obligaciones de las misiones diplomáticas y las organizaciones internacionales respecto al alcance de la inmunidad y las obligaciones del Estado frente a la inmunidad, y en caso de responsabilidad.

Como se explicará a través de la presentación de los casos más relevantes, la jurisprudencia colombiana ha reconocido, adecuadamente, la razón de ser de la inmunidad de las organizaciones internacionales y su relación funcional con el objeto y fin de la organización y la soberanía del Estado

51 Arévalo Ramírez, Walter y García López, Luisa Fernanda, "La interpretación constitucional y sus métodos en el sistema jurídico norteamericano, una interacción entre lo político y lo jurídico: Teorías y casos de estudio Ius et Praxis", vol. 24, núm. 2, 2018, pp. 393-430.

52 Abello Galvis, Ricardo, "La Corte Constitucional y el derecho internacional Los tratados y el control previo de constitucionalidad 1992-2004”, Estudios Socio-Jurídicos, vol. 7, núm. 1, 2005, pp. 305-382.

53 García-Matamoros, Laura Victoria y Arévalo-Ramírez, Walter, "Dos décadas de debates entre la Constitución de 1991 y el derecho internacional. El control constitucional de los tratados, las enmiendas constitucionales y la oposición a sentencias de tribunales internacionales”, De la constitución de 1991 a la realidad. Debates políticos, jurídicos, territoriales e internacionales, Bogotá, Universidad del Rosario, 2015, pp. 347-376.

54 Abello-Galvis, Ricardo, "La Corte Constitucional y el Derecho Internacional. Los tratados y el control previo de constitucionalidad 1992-2007”, Anuario Colombiano de Derecho Internacional, Bogotá, 2008, pp. 263-391, disponible en: http://www.anuariocdi.org/anuariocapitulos-pdf/12_Abello.pdf. 
sede, pero erróneamente ha trasladado las limitaciones consuetudinarias propias de la inmunidad de las misiones diplomáticas — como no conceder inmunidad a nacionales, y excluirla o limitarla en actos comerciales o laborales - a la inmunidad de las organizaciones internacionales, vulnerando esta distinción fundamental y obviando su naturaleza convencional.

En cuanto al primer punto, un buen recuento jurisprudencial ocurre en la motivación de la Sentencia C-254 de 2003, donde la Corte Constitucional reconoce que la inmunidad de las organizaciones internacionales es producto de lo pactado en su acuerdo constitutivo, y que su alcance es de carácter funcional, aceptando que su naturaleza, alcance y limitaciones se someten a lo acordado y concedido en el convenio constitutivo y acuerdo de sede por los Estados parte, y que tal pacto de inmunidad no vulnera per se la soberanía nacional ni el principio de igualdad, como lo decidiera primigeniamente en la Sentencia C-203 de 1995, sobre la ley aprobatoria de tratado del Convenio Constitutivo del Organismo Multilateral de Garantía de Inversiones (OMGI), como se muestra a continuación:

Para comenzar es necesario advertir que la jurisprudencia constitucional ha admitido la introducción de cláusulas de inmunidad en los tratados internacionales como reconocimiento de que las mismas son medios "que han existido para asegurar la independencia de los representantes diplomáticos, y que se han extendido a las organizaciones internacionales, a sus bienes y funcionarios también para asegurar la autonomía de esas entidades". ${ }^{55}$ Adujo en este contexto que la institución de la inmunidad no es per se contraria al ordenamiento jurídico.

Lo mismo subrayó cuando revisó la exequibilidad de la Ley 464 de 1998 que aprobó el "Convenio Internacional de las Maderas Tropicales", suscrito en Ginebra en 1994. El artículo 17 de dicha Convención establece un sistema de inmunidades y privilegios similar al que contiene la Convención sobre asistencia en caso de accidente nuclear o emergencia radiológica. El numeral $3^{\circ}$ de dicho artículo señala que "La organización [Internacional de Maderas Tropicales] podrá concertar con uno o más países acuerdos, que habrán de ser aprobados por el Consejo, sobre las facultades, privilegios e inmunidades que sean necesarios para el debido funcionamiento del presente Convenio".

55 Con referencia a la Corte Constitucional a sus sentencias C-203 de 1995, C-137 de 1996 y C-200 de 1997. 
En relación con esta disposición, que faculta a la organización internacional para establecer regímenes de inmunidades a favor de sus miembros, la Corte adujo que las inmunidades y privilegios conferidos a miembros de organismos internacionales se ajustan a la Carta Política siempre y cuando estén encaminadas a la "defensa, igualdad y soberanía del organismo de derecho internacional de que se trate y de los Estados que acuerdan conceder dichas prerrogativas". ${ }^{56}$ La Corte agregó que de no hacerse tal salvedad, "[b]ajo el manto de buenas intenciones patrocinadas por el Convenio, que la Corte respeta y alienta [...] cláusulas como la analizada pueden constituirse en el germen de tratamientos diferenciales y privilegiados que den cabida a injusticias y desequilibrios”.

Dicha posición refrendó lo sostenido por la Corte en la Sentencia C-137 de 1996 a propósito de la revisión constitucional de la Ley 208 de 1995, por la cual se aprobó el "Estatuto del Centro Internacional de Ingeniería Genética y Biotecnología”, hecho en Madrid en 1983.

Al igual que la Convención sobre el Manejo de Maderas Tropicales, el Estatuto del Centro Internacional de Ingeniería Genética y Biotecnología cuenta con una norma destinada a regular los privilegios e inmunidades de los miembros del Centro. El artículo 13 del Estatuto prescribe, entre otras cosas, que "6. Los funcionarios del Centro gozarán de las prerrogativas e inmunidades que dispone el Artículo V de la Convención sobre Prerrogativas e Inmunidades de las Naciones Unidas”, que “5. Los representantes de los Miembros gozarán de las prerrogativas e inmunidades que dispone el Artículo IV de la Convención sobre Prerrogativas e Inmunidades de las Naciones Unidas”, y que “7. Los expertos del Centro gozarán de las mismas prerrogativas e inmunidades estipuladas para los funcionarios del Centro en el párrafo 6 que antecede”.

Frente a dichas disposiciones la Corte sostuvo que las inmunidades conferidas a los miembros de un organismo internacional son concesiones ofrecidas con fundamento en disposiciones de derecho internacional que no quebrantan por sí mismas el concepto de soberanía nacional. ${ }^{57}$

56 Con referencia a la Corte Constitucional a su Sentencia C- 442 de 1996.

57 Sentencia C-254/03.

"Por otra parte, las disposiciones que consagran privilegios e inmunidades a favor del Organismo creado y de sus directivos y dignatarios se enmarcan dentro de los principios del Derecho Internacional, reconocidos por Colombia según el artículo 9 de la Constitución Política. (...) No puede decirse que la consagración de estos privilegios e inmunidades vulneren el derecho a la igualdad (Artículo 13 C.P.), respecto de personas colombianas, ya que, como la Corte lo ha señalado reiteradamente, la igualdad se predica 
El caso de la Sentencia C-254/03 es relevante pues lo ocurrido en ella, donde justamente la cláusula de inmunidad del tratado decidió excluir a los funcionarios nacionales de la organización de energía atómica que cumplan funciones en Colombia. Esto debería implicar que la Corte Constitucional se hubiera mantenido en la línea de analizar la inmunidad de las organizaciones sin limitarla unilateralmente mediante la indebida aplicación a ella de las limitaciones de la inmunidad diplomática, como ocurrió en los casos siguientes.

La Sentencia C-788 de 2011, relativa al Acuerdo de Cooperación y Régimen de Privilegios e Inmunidades entre la Organización Internacional para las Migraciones y el Gobierno de la República de Colombia, hace una generalización de las limitaciones consuetudinarias a la inmunidad propias de las misiones diplomáticas, y las traslada también a las organizaciones internacionales. A pesar de reconocer que la inmunidad concedida a las mismas no vulnera la soberanía nacional, exceptuando la inmunidad de la organización en situaciones no pactadas en el convenio, aparentemente indica que a las organizaciones internacionales, según la Corte Constitucional colombiana, también aplicarían las limitaciones a la inmunidad.

Las materias que la sentencia indebidamente extiende a las organizaciones internacionales tales limitaciones, incluyen: i) lo laboral, donde las misiones diplomáticas y las organizaciones internacionales al contratar nacionales quedarían suscritas a las prestaciones sociales de ley, lo que no es correcto en el caso de las organizaciones internacionales desde el punto de vista del derecho internacional; ii) en el ámbito extracontractual y en lo relativo al derecho de sucesiones, donde indicó que los miembros del cuerpo diplomático no tienen inmunidad por actos fuera de su función de representación de Estado y deben someterse a la jurisdicción civil, como también para los "actos comerciales", excepción que, como vimos anteriormente, no puede ser aplicada a la organización internacional pues a ella no aplica la diferencia entre actos iure gestionis y iure imperii, y iii) en cuanto a lo administrativo y penal, admitió que debe remitirse a lo pactado sobre la inmunidad de jurisdicción plena, dejando como mecanismo residual, para no afectar

de situaciones iguales, de tal modo que las diferencias de trato pueden admitirse cuando se encuentran justificadas. En el caso de los funcionarios y representantes de organismos internacionales, las normas especiales acordadas entre los estados miembros y la protección que se les brinda tienen su razón de ser en la función que cumplen, como integrantes de delegaciones diplomáticas”. Sentencia C-203 de 1995. 


\section{el principio de igualdad y el igualitario soporte de las cargas públicas, ${ }^{58}$ que los ciudadanos que se vean afectados por la inmunidad deberán proceder a demandar al Estado. ${ }^{59}$}

58 Sentencia C-788 de 2011: "En la sentencia C-315 de 2004, la Corte no hizo ningún reparo. Sin embargo, es preciso aclarar que en la Sentencia C-863 de 2004, al estudiar la constitucionalidad de la Ley 877 de 2 de enero de 2004, "Por medio de la cual se aprueba «la Convención sobre la Seguridad Personal de las Naciones Unidas y el personal asociado», suscrita en Nueva York el 9 de diciembre de 1994, la Corte afirmó que en concordancia con lo dispuesto en dicha convención, el personal de las Naciones Unidas y el personal asociado tienen la obligación de respetar las leyes y reglamentos del Estado receptor. En este sentido, aunque la Corporación consideró constitucional el artículo de la Convención según el cual, el personal militar o de policía asociado a las Naciones Unidas no puede ser detenido ni interrogado cuando haya sido capturado en el curso del desempeño de sus funciones y se haya establecido su identidad, pues "debe ser devuelto a las Naciones Unidas o a las autoridades pertinentes, y en todo caso tratado de conformidad con las normas de derechos humanos universalmente reconocidas y con los principios y el espíritu de los Convenios de Ginebra de 1949”, también fue enfática en sostener que los privilegios de los que goza el personal de Naciones Unidas, "no implican la impunidad frente a posibles delitos cometidos por este personal durante su paso por territorio colombiano. Según las normas penales aplicables, incluso de conformidad con las normas internacionales, los privilegios e inmunidades no tienen como consecuencia la impunidad por los delitos cometidos por agentes amparados por ellas. En el caso de delitos cometidos por personal que goza de privilegios o inmunidades, los derechos de las víctimas a la verdad, la justicia y la reparación deben ser garantizados, por lo que cabe la indemnización de los perjuicios ocasionados a las víctimas, incluso a cargo del Estado colombiano cuando se reúnan los requisitos para ello”.

59 Sentencia C-788 de 2011: "A continuación, se resumen las consideraciones que expuso la Corte en esa oportunidad, en relación con la inmunidad de jurisdicción restringida en materia civil y administrativa: (1) El principio de inmunidad de jurisdicción no implica que la víctima de un daño antijurídico causado por una misión diplomática no pueda obtener la indemnización respectiva. En efecto, de acuerdo con la jurisprudencia sentada por el Consejo de Estado en la materia, si «por un tratamiento de privilegio conferido por el Estado a una persona, atendidas sus calidades, se produce un desequilibrio en su favor y en contra de otro que resulta damnificado y sin la posibilidad de demandar con fundamento en el hecho dañino ante su juez natural, es claro que hay un desequilibrio de las cargas públicas y que por ello el particular está habilitado para demandar al Estado en reparación con fundamento en su actuar complejo (...)». De este modo, el rompimiento del equilibrio de las cargas públicas ocasionado por la actividad legítima del Presidente de la República y el Congreso, que genera un daño antijurídico, impone al Estado el deber de reparar a los afectados. (2) Los locales, archivos, documentos y la correspondencia oficial de la misión diplomática son inviolables. (3) La inmunidad de jurisdicción de los representantes del Estado que envía la misión especial y de los miembros de su personal diplomático «no los eximirá de la jurisdicción del Estado que envía». (4) los representantes del Estado que envía la misión especial y de los miembros 


\section{De igual manera lo ha desarrollado el Consejo de Estado:}

Esta Corporación ha definido en sede de tutela y en materia de control de constitucionalidad, las siguientes limitaciones a la inmunidad de los agentes de Estados extranjeros y organismos de derecho internacional que se encuentren en el territorio nacional:

1. La jurisdicción laboral. En la sentencia T-932 de 2010, la Corte analizó el caso de una ciudadana a favor de quien la Misión Diplomática de la Embajada de la República Bolivariana de Venezuela en Colombia, dejó de realizar los aportes al Sistema de Pensiones. Para resolver el caso concreto, en las consideraciones generales del fallo, la Sala Novena de Revisión llegó a tres conclusiones principales: (i) de manera progresiva, el derecho internacional ha reconocido que los Estados y los organismos internacionales tienen inmunidad restringida en materia laboral, es decir, ha aceptado que las misiones diplomáticas y los organismos supranacionales pueden ser llamados a juicio por tribunales locales "cuando se encuentran comprometidos derechos laborales y prestacionales de connacionales y residentes permanentes del territorio nacional (...); (ii) cuando un Estado extranjero celebra un contrato laboral con un nacional colombiano, debe someterse irrestrictamente a las normas laborales internas, razón por la que "un Estado acreditante no puede alegar inmunidad por reclamos derivados del contrato de trabajo o de la ejecución de relaciones laborales"; y (iii) la celebración de contratos de trabajo con nacionales colombianos obliga a las misiones diplomáticas y a los organismos supranacionales a asumir el riesgo de vejez, "mediante la afiliación del trabajador al Instituto de Seguros Sociales o incluso a otras entidades de previsión social que cubrieran tal riesgo".

En consonancia con las conclusiones anotadas, al constatar que la accionante podía acudir ante los jueces laborales para obtener el amparo de sus pretensiones, y ante la necesidad de adoptar medidas urgentes e impostergables para garantizar la protección de sus derechos fundamentales al mínimo vital y la seguridad social, la Corte concedió la tutela interpuesta como mecanismo transitorio y ordenó al Jefe de la Misión Diplomática de la Embajada de la República Bolivariana de Venezuela en Colombia pagar a la accionante "la suma equivalente a un salario mínimo legal mensual vigente conforme a las normas colombianas, a título de pensión provisional de vejez y hasta tanto la justicia ordinaria laboral resuelva de fondo la con-

de su personal diplomático gozan de inmunidad en el Estado receptor, únicamente por los actos realizados en el desempeño de sus funciones oficiales". 
troversia en materia de derechos laborales que planteará la actora”. Así, se puede concluir que la acción de tutela sí es procedente para obtener la protección de los derechos fundamentales al mínimo vital, al trabajo y a la seguridad social de quien ha prestado sus servicios a una misión diplomática o a un organismo internacional, cuando el empleador ha omitido dar cumplimiento al deber de realizar los aportes correspondientes al Sistema de Pensiones.

2. Las jurisdicciones civil y administrativa. ${ }^{60}$

La Sentencia C-788 de 2011 también deja entrever una curiosa circunstancia en la lógica de la Corte Constitucional que profundiza la dificultad de su aproximación a la inmunidad de las organizaciones internacionales: la Corte Constitucional ha tomado como parámetro generalizable, las limitaciones a la inmunidad pactadas en la "Convención sobre las Misiones Especiales de las Naciones Unidas”, tratado que analizó en la Sentencia C-315 de 2004 y que citó repetidamente en decisiones como la C-788 de 2011. Las limitaciones a la inmunidad allí pactadas no son extensibles a todas las organizaciones internacionales y a sus convenios constitutivos, pero la corte pareciera tomarlo como una guía para entender la inmunidad en sí misma.

Mediante la Sentencia C-315 de 2004, la Sala Plena de esta Corte declaró la constitucionalidad de "La Convención sobre las Misiones Especiales" de las Naciones Unidas — abierta a la firma en Nueva York el 16 de diciembre 1969_-, así como de la Ley aprobatoria 824 de 2003. De acuerdo con el artículo 31 de dicha Convención, los representantes de un Estado y los miembros del personal diplomático gozan de inmunidad civil y administrativa, salvo en estos casos: “a) una acción real sobre bienes inmuebles particulares radicados en el territorio del Estado receptor, a menos que la persona de que se trate los posea por cuenta del Estado que envía para los fines de la misión; b) una acción sucesoria en la que la persona de que se trate figure, a título privado y no en nombre del Estado que envía, como ejecutor testamentario, administrador, heredero o legatario; c) una acción referente a cualquier actividad profesional o comercial ejercida por la persona de que se trate en el Estado receptor, fuera de sus funciones oficiales [y] d) una acción por daños resultante de un accidente ocasionado por un vehículo utilizado fuera de las funciones oficiales de la persona de que se trate". Con fundamento en las disposiciones anteriores, en la citada sentencia, luego de reiterar que el principio de inmunidad

60 Sentencia C-788 de 2011. 
de jurisdicción restringida no contradice la Constitución pues no vulnera por sí mismo el principio de igualdad, la Corte afirmó que los artículos que abordan el tema contenidos en la Convención deben ser entendidos de conformidad con (i) la jurisprudencia del Consejo de Estado en lo concerniente a la jurisdicción administrativa, y (ii) los demás artículos de la misma Convención que se refieren a las obligaciones generales que deben satisfacer los integrantes de una misión diplomática [...] 3. La jurisdicción penal. La citada Convención sobre las Misiones Especiales de las Naciones Unidas, incorporada al ordenamiento jurídico interno por la Ley 824 de 2003, también señala en su artículo 31 que los representantes de un Estado y los miembros del personal diplomático gozan de inmunidad penal en el Estado receptor”.

Esta argumentación y limitaciones extendidas a la inmunidad de las organizaciones internacionales derivadas de la inmunidad diplomática en la Sentencia C-788 de 2011, es replicada en la Sentencia C-267 de 2014 sobre el Acuerdo entre Colombia y La Organización para la Prohibición de las Armas Químicas sobre Privilegios e Inmunidades de la OPAQ. ${ }^{61}$

En el ámbito del control concreto, bajo la acción de tutela por solicitudes de comparecencia éstas se realizaran frente a las organizaciones internacionales por parte de autoridades nacionales o por vía de derecho de petición en protección de los derechos fundamentales. En tal sentido, la Corte Constitucional en los casos siguientes, ha cometido ciertos ires y venires. Por un lado, reconoce las excepciones ya admitidas en sus otras sentencias previamente citadas, por el otro, fortalece el criterio de inmunidad de jurisdicción penal, pero ha recalcado que tanto misiones diplomáticas como organizaciones internacionales tendrían que comparecer en lo laboral, situación que contradice el estado actual del derecho internacional en la materia explicado en la primera parte de este artículo.

La Corte Constitucional en la Sentencia T-611 de 2011, recopila $\operatorname{casos}^{62}$ en que organizaciones internacionales con sede en su territorio han sido lla-

61 Sentencia C-267 de 2014 sobre tutela a organizaciones internacionales:

62 “5.2.1 El tema del principio de inmunidad de jurisdicción frente a la procedibilidad de la acción de tutela contra organismos internacionales para obtener la protección del derecho fundamental de petición, únicamente ha sido abordado por la Corte en tres sentencias, por lo que en seguida se hará una breve referencia a cada una de ellas:

5.2.1.1 En la sentencia T-883 de 2005, la Corte estudió las sentencias proferidas en el trámite de la acción de tutela instaurada por un ciudadano contra el Programa de las Naciones 
madas a responder peticiones de autoridades o ciudadanos y compara la obligación inexorable de las misiones diplomáticas de atender estas solicitudes, laborales y de derecho de petición, que tienen las misiones diplomáticas, con el "deber" de comparecencia que tienen según ella las organizaciones internacionales, que ejercerán bajo la potestad de dictaminar si comparecen o no, siempre que hacerlo, según su propio juicio, no afecte su objeto y fin. Este última prueba, aunque más favorable que una eliminación total de la inmunidad en la materia, tampoco corresponde con los preceptos ya explicados que el derecho internacional contempla a la inmunidad funcional plena de carácter convencional de las organizaciones internacionales.

Ejemplo de lo anterior es la Sentencia T-611 de 2011:

Para resolver el caso concreto, en aplicación de la tesis desarrollada en la Sentencia T-883 de 2005, ya citada, la Sala Séptima de Revisión afirmó:

Unidas para el Desarrollo (PNUD), por considerar que dicho programa vulneró sus derechos fundamentales de petición y honra.(...) Para resolver el caso concreto, en las consideraciones generales de la sentencia, la Sala Quinta de Revisión explicó que en el ámbito constitucional, el principio de inmunidad de jurisdicción debe atender a varios aspectos. En primer lugar, señaló que el principio en comento «no puede entenderse como una habilitación que ampara conductas arbitrarias y que pueden resultar lesivas de derechos consagrados y protegidos por el ordenamiento interno», pues la inmunidad otorgada por el Estado colombiano a un organismo de derecho internacional, solo puede ser considerada constitucional si responde «a la necesidad de asegurar la independencia y neutralidad de las labores que desarrolle el sujeto de derecho internacional correspondiente». En segundo lugar, sostuvo que dada la tendencia actual seguida por la mayoría de Estados de conceder inmunidad restringida a autoridades extranjeras, «es posible que el texto mismo del tratado o convenio respectivo, establezca el mecanismo a través del cual se pueden solucionar las controversias en las que se vean involucrados sujetos que gozan de inmunidades reconocidas por los Estados, con lo que se garantiza, además, la protección efectiva de los derechos de los individuos[25]».Y en tercer lugar, concluyó que ante la necesidad de garantizar la protección de los derechos vulnerados, particularmente del derecho al acceso a la administración de justicia, «en los casos en los que la protección del derecho exija la realización de determinada conducta por el sujeto que goza de inmunidad, podría el afectado solicitar al Estado colombiano que supla la actuación del funcionario u organización respectiva, en el evento en que ello fuere posible, toda vez que por esa vía se garantizarían los derechos de la persona, respetando la inmunidad que fue reconocida por el Estado».

Con fundamento en lo anterior, la Corte negó el amparo de los derechos fundamentales invocados, al estimar que era el Ministerio de Hacienda y Crédito Público en calidad de organismo ejecutor del Proyecto para la Modernización de la Administración Financiera Pública, y no el PNUD, la entidad encargada de dar respuesta a la petición presentada por el actor”. 
“Ahora bien, en el caso concreto el demandante interpuso la acción de tutela contra el PNUD por la supuesta violación de su derecho fundamental de petición, razón por la cual pareciera necesario indagar si realmente la actuación del organismo internacional afectó el derecho invocado y si dicho organismo puede ser demandado en sede de tutela para reparar tal afectación. No obstante, encuentra la Sala que en el presente caso existe una instancia estatal a la cual puede imputársele también la vulneración del derecho invocado y la cual adicionalmente esta en capacidad de reparar la trasgresión, pues el juez de primera instancia vinculó al trámite de la tutela a la Alcaldía Mayor de Bogotá, sobre cuya legitimidad pasiva no existen dudas y la cual, adicionalmente, ha actuado a lo largo del presente proceso como sujeto demandado. Cabe recordar también que el Sr. Fernández de Soto Londoño inicialmente formuló una petición, en idéntico sentido a la posteriormente formulada al PNUD, a la Alcaldía Mayor de Bogotá, la cual fue respondida en sentido negativo.

Las anteriores razones llevan a concluir que en el presente caso existe una instancia estatal que funge como responsable de la presunta vulneración del derecho de petición, la cual ha sido vinculada al trámite de la acción de tutela, razón por la cual no es preciso — en esta específica oportunidad — pronunciarse sobre las inmunidades del organismo internacional y sobre su responsabilidad en la afectación de los derechos fundamentales del peticionario. Máxime cuando el proceso de contratación, en el cual tuvo origen la disputa iusfundamental, tiene como beneficiario a la entidad distrital (Negrilla fuera del texto original).

Por lo anterior, la Corte tuteló el derecho fundamental de petición del accionante y ordenó a la Alcaldía Mayor de Bogotá entregarle la información requerida.

5.2.2 Ahora bien, aunque de manera general se comparte la posición jurisprudencial de la Corte expuesta anteriormente, se estima que la misma no ha tenido en cuenta aspectos de vital importancia que permitirían conciliar de mejor manera la prevalencia de los derechos fundamentales en el ordenamiento jurídico interno y el principio de inmunidad de jurisdicción restringida de los organismos internacionales.

5.2.2.1 En efecto, de conformidad con el artículo 23 de la Constitución, como ya se explicó, toda persona tiene derecho a presentar peticiones respetuosas "a las autoridades" por motivos de interés general o particular y a obtener pronta resolución" (Negrilla fuera del texto original).

5.2.2.2 Al respecto, esta Corporación ha señalado que el término "autoridad” puede ser definido como la "potestad de que se halla investida una persona, que proviene del Estado y que comporta la obligatoriedad de sus decisiones para quie- 
nes se encuentran subordinados a ella...”. Sin embargo, frente al derecho fundamental de petición, como se dijo en el fundamento jurídico cuatro de esta providencia, la Corte Constitucional ha sostenido que ese derecho puede ser ejercido contra particulares, esencialmente en dos casos: (i) cuando el particular presta un servicio público o realiza funciones públicas; y (ii) en el evento en que la protección de otro derecho fundamental haga necesaria la respuesta o la ausencia de respuesta sea lesiva de otro derecho fundamental.

5.2.2.3 En este sentido, es claro que los organismos internacionales no son autoridades públicas, pues no ejercen dominio sobre los ciudadanos, y tampoco particulares en sentido estricto dado el régimen de privilegios al que se encuentran sujetos, según los convenios y tratados que se suscriban para el efecto.

5.2.2.4 Empero, desde la perspectiva del principio de inmunidad de jurisdicción restringida y en virtud de la soberanía del Estado colombiano, se considera que los organismos internacionales sí estarían obligados a dar respuesta directa a las peticiones respetuosas presentadas por los ciudadanos en el territorio nacional, en principio, en los siguientes supuestos:

(1) Cuando la respuesta a la petición no amenace la soberanía, independencia e igualdad de los Estados; y en el caso de los organismos y agencias internacionales, no ponga en riesgo la autonomía que necesitan para el cumplimiento de su mandato.

(2) Cuando de la respuesta a la petición dependa la protección de los derechos fundamentales al mínimo vital, al trabajo y a la seguridad social de quien tenga una relación de subordinación respecto de la misión diplomática o el organismo internacional.

(3) Cuando de la respuesta a la petición presentada dependa la protección de "derechos laborales y prestacionales de connacionales y residentes permanentes del territorio nacional”.

Se estima que los supuestos anotados no lesionan el principio de inmunidad restringida de los organismos internacionales y las misiones diplomáticas, porque no solo son respetuosos del artículo 9 de la Constitución Política; también tienen en cuenta que en virtud de la jurisprudencia constitucional, los privilegios e inmunidades de los Estados y las agencias internacionales huéspedes en Colombia no son absolutos, comoquiera que están supeditados a la garantía de intereses superiores como la independencia, igualdad y soberanía de los Estados, y la autonomía de los organismos internacionales.

De igual manera, dichos supuestos no son contrarios al principio de prevalencia de los derechos fundamentales, porque reconocen la obligación del Estado colom- 
biano de asegurar la defensa de los derechos de las personas sometidas a su jurisdicción, cuando esos derechos sean vulnerados por personas naturales o jurídicas que gozan de inmunidad.

En este sentido, los supuestos enunciados guardan correspondencia con los fundamentos esenciales por los cuales las inmunidades y privilegios otorgados a los organismos de derecho internacional son constitucionales, y al mismo tiempo con el reconocimiento que ha hecho la jurisprudencia sobre el carácter restringido de la inmunidad de jurisdicción, particularmente en materia laboral. ${ }^{63}$

Sobre la misma tendencia, de limitación no convencional de la inmunidad de las organizaciones internacionales que pueda implicar para la Corte Constitucional su obligación o "deber" de comparecencia, otra decisión de tutela, la Sentencia T-093 de 2012, reafirma la inmunidad de jurisdicción y de ejecución, pero curiosamente afirma que Colombia ha sido parte del proceso histórico en el que las inmunidades diplomáticas se van trasladando al ámbito de las organizaciones internacionales, donde la corte erróneamente traspasa a las segundas, las excepciones emanadas de la costumbre para las primeras, criterio que como se ha reiterado, no es admisible:

4.2.1. El Estado colombiano ha reconocido que las inmunidades y prerrogativas que concede el país a funcionarios de organizaciones internacionales o representantes diplomáticos de otros Estados, en garantía de la necesidad de asegurar la independencia y neutralidad de las labores que desarrolle el sujeto de derecho internacional correspondiente, armonizan con las disposiciones de la Constitución Política. Se trata, principalmente, de la Convención sobre Privilegios e Inmunidades de Naciones Unidas, del 13 de febrero de 1946, ratificada por Colombia mediante la Ley 62 de 1973, instrumento del que Colombia es parte y se encuentra obligado ya que no lo ha denunciado, ni ha condicionado o ha hecho reserva de alguna de sus disposiciones.

4.2.2. La inmunidad, para el caso que nos ocupa, constituye, entonces, una regla de carácter procesal que opera como excepción y que reviste dos manifestaciones fundamentales: (i) la inmunidad de jurisdicción como tal, que se refiere a la incompetencia de los jueces nacionales para juzgar a determinados sujetos de derecho internacional, que pueden ser otros Estados u organizaciones internacionales

63 Sentencia T-611 de 2011. 
y (ii) la inmunidad de ejecución, la cual impide que se haga efectiva determinada decisión judicial, en caso de que el procedimiento contra el sujeto de derecho internacional se hubiere llevado a cabo. Al respecto, la Corte ha expresado:

... del principio de soberanía, independencia e igualdad de los Estados se deriva una regla de derecho internacional público, reconocida por la costumbre y las convenciones internacionales en virtud de la cual los agentes y bienes de Estados extranjeros deben ser inmunes frente a la actuación coercitiva de las autoridades públicas de los Estados huéspedes. Este principio se hizo extensivo a los funcionarios y bienes de las agencias o centros internacionales a fin de garantizar, fundamentalmente, la independencia de dichos organismos en el cumplimiento de sus funciones, donde quiera que, en virtud de un acuerdo internacional, operaran. ${ }^{64}$

En conclusión, la recepción y desarrollo de los preceptos de inmunidad explicados anteriormente por parte de la jurisdicción colombiana es contradictoria y problemática. La jurisprudencia colombiana, como se evidencia en las decisiones previamente explicadas, no identifica correctamente la naturaleza de las fuentes que gobiernan cada tipo de inmunidad — la diplomática y la de las organizaciones internacionales - , generando confusiones sobre las restricciones que son admisibles a la misma.

En primer lugar, en varias sentencias de su primera época o primera corte, como la C-203 de 1995, y gran cantidad de sentencias posteriores que la citan, como las C-254 de 2003, la Corte Constitucional reconoce la naturaleza funcional y convencional de la inmunidad de las organizaciones internacionales, lo que debería ser fundamento jurisprudencial para que las autoridades nacionales y ella misma reconocieran que se trata de una inmunidad que se estudia caso por caso y de ser pactada como plena para una organización, así debe mantenerse y solo serán aplicables a ella las excepciones emanadas de su propio convenio constitutivo, por ejemplo, la excepción de no extender a nacionales funcionarios de la organización ninguna inmunidad, como se pactó en el instrumento analizado por la Sentencia C-254 de 2003.

Posteriormente, en un conjunto amplio de sentencias cuyos argumentos terminan condensados y recogidos en las decisiones C-788 de 2011 (Acuerdo de Cooperación y Régimen de Inmunidades entre la Organización Inter-

64 Sentencia T-093 de 2012. 
nacional para las Migraciones y el Gobierno de Colombia) y la C-267 de 2014 (Acuerdo entre Colombia y la Organización para la Prohibición de las Armas Químicas sobre Privilegios e Inmunidades de la OPAQ), comienza un fenómeno jurisprudencial tan confuso como curioso: la Corte Constitucional empieza a traer las excepciones derivadas de la costumbre, aplicadas a la inmunidad diplomática, que ha tenido oportunidad de conocer entre sus inicios (1994) y esta segunda década (2010 en adelante) por vía de sentencias de tutela frente a problemas concretos de inmunidad de misiones diplomáticas en incumplimiento de contratos y controversias laborales, y las hace aplicables a los estudios de control abstracto de las leyes aprobatorias de tratado de los acuerdos de inmunidad de las organizaciones internacionales, no solo generando la confusión de que ambos tipos de inmunidad son gobernados por la costumbre, sino generando el difícilmente sostenible argumento a nivel internacional, de que la inmunidad de las organizaciones es per se restringida, cuando en realidad su alcance restringido o pleno derivada del convenio.

Esto deriva en situaciones complejas para la defensa de la inmunidad internacional, según se ha pactado en los tratados en el caso de las organizaciones internacionales en la jurisdicción colombiana, que se evidencian en decisiones de la misma época o un poco posteriores, donde por vía de control concreto, sentencias de tutela, se acciona en contra de las organizaciones internacionales, como las referidas sentencias T-883 de 2005, T-611 de 2011 y T-093 de 2012 y en donde la Corte Constitucional, contrario al estándar internacional explicado al inicio del artículo, termina de consolidar tres impropiedades fundamentales frente a las organizaciones internacionales y su inmunidad.

En primer lugar, derivar de su concepción restringida de la inmunidad, la idea de que puede adicionar o presumir limitaciones a la inmunidad de las organizaciones internacionales que no estén pactadas en el tratado, muchas de ellas, meras asimilaciones de las limitaciones consuetudinarias de la inmunidad diplomática, como los asuntos laborales, extracontractuales o sucesorales. Ya existe en el precedente comparado, un importante número de casos, como Broadbent vs. OAS, donde tribunales de superior jerarquía indicaron que no se podían someter a la legislación nacional asuntos laborales si esa excepción no estaba pactada en el convenio constitutivo y que la restricción a la inmunidad en materia laboral no se puede presumir. Véase el siguiente ejemplo: 
Treatise writers on the law of international organizations have recognized the force of the argument made in text. See, e. g., M. B. Akehurst, The Law Governing Employment in International Organizations 12 (1967), which discusses suits such as the instant case in the following terms:

At first sight, disputes of this sort could be referred to municipal tribunals. The organization normally possesses immunity, but immunity can be waived. However, the special nature of the law governing employment in international organizations, closely linked as it is with delicate questions of administrative policy, makes municipal tribunals totally unsuited to deal with it. It would be like an english court trying to judge a dispute between the french government and one of its officials. Courts in all countries usually refuse to handle questions of foreign public law, and, in the same way, a number of municipal courts have held themselves incompetent to judge claims brought by international civil servants against the organizations which employ them, not on the grounds of immunity, but on the grounds of the special law applicable.

There is therefore a vacuum which needs to be filled by the organizations themselves. The creation of an independent body, empowered to make binding decisions in legal disputes between an organization and its staff, is by no means an altruistic gesture from the organization's point of view; without it, officials might suffer from a sense of injustice which would impair the smooth running of the Secretariat.

The court notes that the OAS, like most international organizations, has established elaborate internal grievance machinery.

We hold that the relationship of an international organization with its internal administrative staff is noncommercial, and, absent waiver, activities defining or arising out of that relationship may not be the basis of an action against the organization — regardless of whether international organizations enjoy absolute or restrictive immunity. ${ }^{65}$

En segundo lugar, desarrollar una doctrina, contradictoria en su seno, de un deber de comparecencia de las organizaciones internacionales, genérico a todas ellas, frente a instrumentos constitucionales como el derecho de petición cuando se encuentren involucrados derechos fundamentales, pero a la vez, dándoles la salvaguarda de no comparecer si las mismas organizaciones consideran que la solicitud afecta su independencia y su objeto y fin, y por tercero y último, en el proceso aplicar mal la doctrina del Consejo de

65 Broadbent v. Organization of Am. States, 628 F.2d 27, D.C. Cir., 1980. 
Estado en la materia, pues las decisiones de aquel han implicado tanto la no comparecencia de la organización internacional, como el desarrollo claro del principio de que como contracarga de la inmunidad de las organizaciones internacionales, será el Estado el que salga a atender las demandas de terceros que puedan involucrar organizaciones internacionales, las cuales no deberán comparecer y será el Ministerio de Relaciones Exteriores el que asista al proceso, y el Estado el que repare en caso de daño. ${ }^{66}$

\section{CONCLUSIÓN}

Como conclusión, consideramos necesario un ajuste y separación clara de los dos tipos de inmunidad y su alcance en la jurisdicción colombiana, para evitar que esta afectación a la inmunidad de las organizaciones internacionales derive en arbitrariedades de los jueces y autoridades nacionales, que bajo estos mismos preceptos, podrían seguir derivando excepciones de la inmunidad diplomática y aplicarlas a las organizaciones internacionales de manera generalizada y sin observar lo pactado en su convenio constitutivo y acuerdo de sede.

Estos errores podrían derivar incorrectamente en que los funcionarios nacionales de una organización internacional no cuenten con la inmunidad pactada por el solo hecho de ser nacionales, o construir, localmente, limitaciones a la inmunidad en materia tributaria de tales funcionarios, las reglas migratorias que deben atender, imponerles procedimientos de acreditación que no fueron pactados en el tratado de la organización y que son propios del ámbito de la inmunidad diplomática, entre otras conductas que constituirían en sí mismas una violación a la inmunidad de la organización y al convenio constitutivo, y con ello, un hecho internacionalmente ilícito generador de responsabilidad internacional, violando por demás la obligatoriedad de los tratados como pilar del derecho internacional, principio reconocido por Colombia. ${ }^{67}$

66 Véase Acción de tutela 41001 -23-33-000-2019-00436-0 1. Sentencia segunda instancia. Consejo de Estado, Colombia. Sala de lo contencioso administrativo. Sección quinta. Magistrada ponente : Rocio Araujo, 31 de octubre de 2019.

67 Sentencia C-358 de 1997. 
Estas violaciones y limitaciones a la inmunidad de las organizaciones internacionales, justamente como lo ha reconocido la Corte Internacional de Justicia en su famosa opinión consultiva de 1949 conocida como "Reparation for Injuries Suffered in the Service of the United Nations", ${ }^{68}$ pueden generar un derecho a la organización internacional, como sujeto del derecho internacional, de invocar la responsabilidad internacional contra el Estado y la reparación del daño por todos los mecanismos diplomáticos y jurisdiccionales a su alcance.

\section{AGRADECIMIENTOS}

El presente artículo es parte de los resultados de la línea de investigación "El derecho internacional a la luz de los diferentes tribunales internacionales" del Observatorio de Derecho Internacional del Anuario Colombiano de Derecho Internacional (ACDI), del Grupo de Investigación en Derecho Internacional de la Facultad de Jurisprudencia de la Universidad del Rosario.

VII. BIBLIOGRAFÍA

Abello-Galvis, Ricardo, "La Corte Constitucional y el derecho internacional. Los tratados y el control previo de constitucionalidad 1992-2004”, Estudios Socio-Jurídicos, vol. 7, núm. 1, 2005.

Abello-Galvis, Ricardo, "La Corte Constitucional y el derecho internacional. Los tratados y el control previo de constitucionalidad 19922007”, Anuario Colombiano de Derecho Internacional, Bogotá, año 1, núm. 1, 2008, disponible en: http: / /www.anuariocdi.org/anuario-capitulos-pdf/ 12_Abello.pdf.

ABELLO-GALVIS, Ricardo, "La costumbre como fuente de derecho internacional: una caja de pandora imposible de cerrar”, Derecho internacional:

68 "Reparation for injuries suffered in the service of the United Nations", Opinión Consultiva, ICJ Rep 174, ICGJ 232, 1949. 
varias visiones, un maestro. Liber amicorum en homenaje a Marco Gerardo Monroy Cabra, Bogotá, Universidad del Rosario, 2015.

AlmEIDA, Paula Wojcikiewicz, "L'affaire des immunités juridictionnelles de l'Etat (Allemagne c. Italie): la Cour Internationale de Justice à contre-sens de l'évolution du droit international", Anuario Colombiano de Derecho Internacional, vol. 11, Bogotá, 2018.

ARÉVALO-RAmÍREZ, Walter y GARCÍA LÓPEZ, Luisa Fernanda, "La interpretación constitucional y sus métodos en el sistema jurídico norteamericano, una interacción entre lo político y lo jurídico. Teorías y casos de estudio", Ius et praxis vol. 24, núm. 2, 2018.

ARÉVAlO-RAmíREZ, Walter, “Organizaciones Internacionales”, Manual de derecho internacional público. Fundamentos, tribunales internacionales y casos de estudio, 2a. ed., Bogotá, Tirant lo Blanch, 2020.

BARKer, J. Craig; COlin, Warbrick y MCGOldRICK Dominic, "State Immunity, Diplomatic Immunity and Act of State: A Triple Protection against Legal Action?" International and Comparative Law Quarterly, vol. 47, núm. 4. 1998.

Berenson, William M. "Squaring the Concept of Immunity with the Fundamental Right to a Fair Trial: The Case of OAS", The World Bank Legal Review, 2012.

BONyUET LEE, Díckar y PÉREZ PACHECO, Yaritza, "Sobre la independencia de los tribunales arbitrales CIADI", Anuario Mexicano de Derecho Internacional, México, vol. XX, 2020, disponible en: https://revistas.juridicas. unam. $\mathrm{mx}$ /index. php/derecho-internacional/article/view/ 14477.

BROWN, Jonathan. "Diplomatic Immunity: State Practice under the Vienna Convention on Diplomatic Relations", International and Comparative Law Quarterly, vol. 37, núm. 1, 1988.

Evans, Malcolm, International Law, 2a. ed., Oxford, Oxford University Press, 2006.

Evans, Malcolm, International Law, 5a. ed., Oxford, Oxford University Press, 2018.

Flor PATIÑO, Imanol de la y PORTILla GómeZ, Juan Manuel, "Las inmunidades diplomáticas en el derecho comparado (México-Estados Unidos) y en el derecho internacional", Anuario Mexicano de Derecho Internacional, México, vol. XVI, 2016. 
Gaillard, Emmanuel y PINGEL-LenuZZA, Isabelle, "International Organizations and Immunity from Jurisdiction: to Restrict or to Bypass", International \& Comparative Law Quarterly, vol. 51, 2002.

García-Matamoros, Laura Victoria y ArÉVAlO-RAmírez, Walter, "Dos décadas de debates entre la Constitución de 1991 y el derecho internacional. El control constitucional de los tratados, las enmiendas constitucionales y la oposición a sentencias de tribunales internacionales", De la constitución de 1991 a la realidad. Debates políticos, jurídicos, territoriales e internacionales, Bogotá, Universidad del Rosario, 2015.

GazzINI, Tarcisio, "Personality of International Organizations", en KLABBers, Jan y Wallendahl, Åsa (eds.), Research Handbook on the Law of International Organizations, Edward Elgar Publishers, 2011.

GODIO, Leopoldo, "Evolución, actualidad y tendencias en materia de privilegios e inmunidades de organismos internacionales", RECORDIP, vol. 1, núm. 2. 2011.

JenKs, Clarence Wilfred, The Proper Law of International Organizations, 1962. KLAbBERS, Jan, An Introduction to International Organizations Law, 3a. ed., Cambridge University Press, 2015.

MACLEAn, Robert Joseph-Blaise y ARÉVALO-RAmíreZ, Walter, “The Expulsion of Resident Colombian Nationals During the Colombia-Venezuela Border Dispute: An «under the Radar» Case for Diplomatic Protection of Human Rights?” Universitas, vol. 68, núm. 138, 2019.

MiLler, Anthony, "Privileges and Immunities of United Nations Officials", International Organizations Law Review, vol. 4, núm. 2, 2008.

O'KeEFE, Patrick J., "Privileges and Immunities of the Diplomatic Family", International and Comparative Law Quarterly, vol. 25, 1976.

OKEKE, Edward Chukwuemeke, Jurisdictional Immunities of States and International Organizations, Oxford, Oxford University Press, 2018.

PAjuste, Tiina, "The Evolution of the Concept of Immunity of International Organizations”, East-West Studies: Journal of Social Sciences of Tallinn University Law School, vol. 8, 2018.

Portilla Parra, Sebastian y Rodríguez Bolaños, Maicol Andrés, "Aplicación y límites de la inmunidad diplomática, a la luz de las normas del «ius cogens»”, Opinión Jurídica, vol. 19, núm. 38, 2020.

Quintana Aranguren, Juan José y Guzmán Carrasco, Gonzalo, "De espaldas al derecho internacional: Colombia y la inmunidad de juris- 
dicción de los Estados", International Law: Revista Colombiana de Derecho Internacional, núm. 8. 2006.

ReINISCH, August, "Contracts between International Organizations and Private Law Persons”, Max Planck Encyclopedia of Public International Law, vol. 7, 2006.

ReINISCH, August, International Organizations before National Courts, Cambridge, Cambridge University Press, 2000.

Rios, Greta L. y FlAHERTY, Edward P., "International Organization Reform of Impunity-Immunity is the Problem”, ILSA J. Int'l \& Comp. L., vol. 16, 2009.

TÉllez NuÑEZ, A., "Aproximación multidimensional al régimen de responsabilidad internacional y al principio de no intervención. El problema hermenéutico", Anuario Colombiano de Derecho Internacional, vol. 13, 2020, disponible en: https: / / doi.org/10.12804/revistas.urosario.edu.co/ac di/a. 7492.

Tesfagabir, Kibrom, "The State of Functional Immunity of International Organizations and their Officials and why it Should be Streamlined", Chinese Journal of International Law, vol. 10, núm. 1, 2011.

Van Ert, Gib; Allen Greg J. y RobB Rebecca, "Canadian Cases in Public International Law in 2013", Canadian Yearbook of International Law, vol. 51, 2013.

VARGAS, Juan Carlos y RODRIGUEZ-WeIL, Eduardo. "La inmunidad de jurisdicción y ejecución de las organizaciones internacionales: un tema antiguo con relevancia actual”, Anuario Hispano-Luso-Americano de Derecho Internacional, vol. 21, 2013.

WooD, Michael, "International Organizations and Customary International Law”, Vanderbilt Journal of Transnational Law, vol. 48, núm. 3, 2015. 